\title{
Characterization of fluorescent proteins with
} intramolecular photostabilization

Sarah S. Henrikus ${ }^{1,2, \#, ~ K o n s t a n t i n o s ~ T a s s i s ~}{ }^{1}$, Lei Zhang ${ }^{3}$, Jasper H. M. van der Velde ${ }^{1}$, Christian Gebhardt $^{3}$, Andreas Herrmann ${ }^{4,5}$, Gregor Jung ${ }^{2}$ \& Thorben Cordes ${ }^{1,3, *}$

${ }^{1}$ Molecular Microscopy Research Group, Zernike Institute for Advanced Materials, University of Groningen, Nijenborgh 4, 9747 AG Groningen, The Netherlands

${ }^{2}$ Biophysical Chemistry, Saarland University, Campus Building B2.2, 66123 Saarbrücken, Germany

${ }^{3}$ Physical and Synthetic Biology, Faculty of Biology, Ludwig-Maximilians-Universität München, Großhadernerstr. 2-4, 82152 Planegg-Martinsried, Germany

${ }^{4}$ Department of Polymer Chemistry, Zernike Institute for Advanced Materials, University of Groningen, Nijenborgh 4, 9747 AG Groningen, The Netherlands

${ }^{5}$ DWI - Leibniz Institute for Interactive Materials, Forckenbeckstr. 50, 52056 Aachen, Germany

\#current address: Molecular Horizons Institute and School of Chemistry, University of Wollongong, Wollongong, NSW, 2500, Australia

*corresponding author email: cordes@bio.Imu.de

Abstract: Genetically encodable fluorescent proteins have revolutionized biological imaging in vivo and in vitro. Since there are no other natural fluorescent tags with comparable features, the impact of fluorescent proteins for biological research cannot be overemphasized. Despite their importance, their photophysical properties, i.e., brightness, count-rate and photostability, are relatively poor compared to synthetic organic fluorophores or quantum dots. Intramolecular photostabilizers were recently rediscovered as an effective approach to improve photophysical properties. The approach uses direct conjugation of photostablizing compounds such as tripletstate quenchers or redox-active substances to an organic fluorophore, thereby creating high local concentrations of photostabilizer. Here, we introduce an experimental strategy to screen for the effects of covalently-linked photostabilizers on fluorescent proteins. We recombinantly produced a double cysteine mutant (A206C/L221C) of $\alpha$-GFP for attachment of photostabilizermaleimides on the $ß$-barrel in close proximity to the chromophore. Whereas labelling with photostabilizers such as Trolox, Nitrophenyl, and Cyclooctatetraene, which are often used for organic fluorophores, had no effect on $\alpha$-GFP-photostability, a substantial increase of photostability was found upon conjugation of $\alpha$-GFP to an azobenzene derivative. Although the mechanism of the photostabilizing effects remains to be elucidated, we speculate that the higher triplet-energy of azobenzene might be crucial for triplet-quenching of fluorophores in the near-UV and blue spectral range. Our study paves the way towards the development and design of a second generation of fluorescent proteins with photostabilizers placed directly in the protein barrel by methods such as unnatural amino acid incorporation. 


\section{Introduction}

Fluorescent proteins (FPs) have revolutionized fluorescence imaging of biological systems in vivo and in vitro. Because they are genetically encoded, they allow the tethering of a natural light-emitting protein chromophore to any protein of interest ${ }^{1-3}$. Since there are no other fluorescent tags with these properties, the impact of FPs for biological research cannot be overemphasized ${ }^{1,3-5}$. Despite their importance, the photophysical properties of FPs, i.e., brightness, count-rate and photostability ${ }^{6-8}$, are relatively poor compared to synthetic organic fluorophores ${ }^{9}$ or quantum dots ${ }^{10-11}$. Extensive research has been done over the past decades to improve the photophysical properties of $\mathrm{FPs}^{12}$. These studies have resulted in numerous FP-variants ${ }^{13-15}$ with useful chemical and photophysical properties, such as variants optimized for fast folding $^{16-17}$, photoswitching ${ }^{18}$, and brigthness ${ }^{8,} 19-20$, or for functions such as $\mathrm{pH}$ sensing ${ }^{21}$. Yet, there are no FPs with photophysical properties that can compete with synthetic dyes in terms of brightness and photostability ${ }^{6}$.

Intramolecular triplet-state quenchers were recently rediscovered as an attractive approach for photostabilization in various fluorescence applications ${ }^{22-23}$. The approach developed in the $1980 \mathrm{~s}^{24-25}$ uses direct conjugation of photostablizing compounds such as triplet-state quenchers or redox-active substances to a fluorescent reporter (typically a synthetic organic fluorophore), thereby creating high local concentrations of photostabilizer around the fluorophore ${ }^{27}$. As illustrated in Figure 1, this improves the photophysical properties of organic dyes such as Cy5 in bulk and single-molecule investigations via intramolecular quenching of triplet or radical states, or; photoinduced electron transfer reactions (mediated in the concrete example by the nitrophenylalanine (NPA) group; data from ref ${ }^{27}$ ).
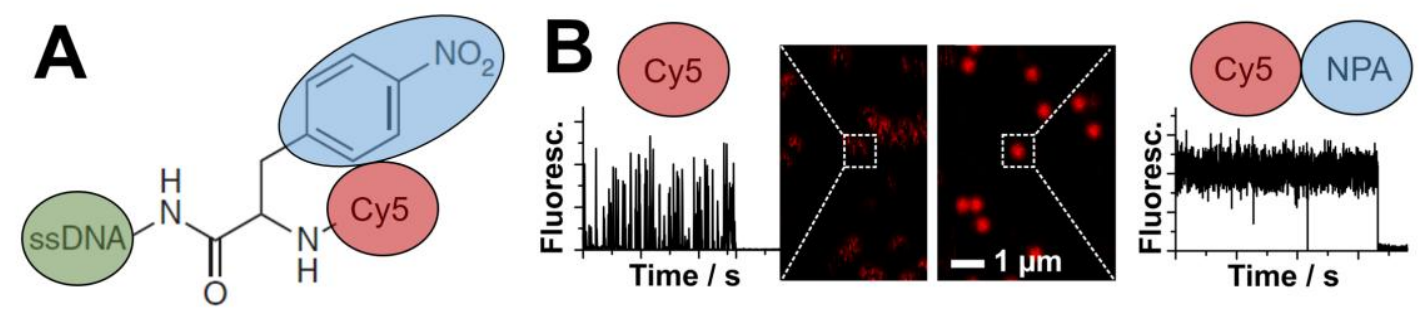

Figure 1. A) Structure of a self-healing organic NPA-Cy5 fluorophore on an oligonucleotide structure 
(ssDNA). B) Experimental demonstration of photostability increases of Cy5 that are simultanously coupled to a biomolecule (left) and to a photostabilizer (right). Analysis of single-molecule fluorescence microscopy data shows temporal behaviour of fluorescence emission of 'self-healing' fluorophore and confocal scanning images and time traces from self-healing Cy5 fluorophores on oligonucleotides. Data reprinted from ${ }^{27}$.

Such a strategy obviates the need for complex buffer systems, and makes these dyes with intramolecular photostabilization "self-healing", and thus compatible with diverse biological systems $22-23,26-29$. This is a particular advantage in situations in which the fluorescent dye is inaccessible to exogenously added stabilizers (e.g., when contained in certain biological cell-compartments ${ }^{30}$ ). Based on new mechanistic insights $^{31-32}$, there has been exciting progress on the optimization of the photostabilization efficiencies in self-healing dyes ${ }^{30,} 33-35$, the development of bioconjugation strategies for different fluorophore types ${ }^{27}$, photostabilizers and biomolecules $^{27,36}$, and their new applications in super-resolution ${ }^{22,27,37}$, live-cell and single-molecule imaging. All this activity, however, has so far been focused on the major classes of synthetic organic fluorophores including rhodamines $23,27,33,37$, cyanines $^{22,27-28,30,34-35}$, carbopyronines ${ }^{37}$, bophy-dyes ${ }^{38}$, oxazines ${ }^{36}$ and fluoresceins ${ }^{36}$. The recent direct and unambiguous demonstration of the formation of a long-lived chromophore triple state in green fluorescent proteins ${ }^{39}$ suggests that intramolecular photostabilization may be a strategy applicable to fluorescent proteins as well.

The green fluorescent protein (GFP) was discovered by Shimomura et al. in the jellyfish Aequorea victoria (avGFP) in $1962^{5}$. The $27 \mathrm{kDa}$ protein shows a secondary structure made up of eleven $\beta$-strands, two short $\alpha$-helices and the chromophore in the center. The $\beta$-strands form an almost perfect barrel, which is capped at both ends by $\alpha$-helices ${ }^{40}$. Therefore the para-hydroxybenzylidene-imidazolinone chromophore in the center of the $\beta$-barrel is completely separated from exterior ${ }^{41}$. The dimension of the cylinder are 4.2 by $2.4 \mathrm{~nm}$. Proper folding is required for autocatalytic maturation of the chromophore from the amino acids Ser65, Tyr66 and Gly6741. GFP shows green fluorescence after excitation in the near UV and blue spectral region. A major and minor absorption peak at $395 \mathrm{~nm}$ and $475 \mathrm{~nm}$, respectively, describes the spectral 


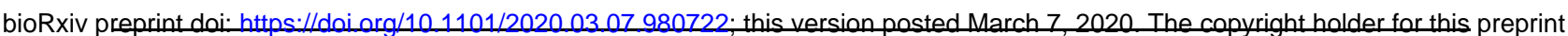
(which was not certified by peer review) is the author/funder. All rights reserved. No reuse allowed without permission.

characteristics of GFP. Fluorescence emission occurs either at $503 \mathrm{~nm}$ (excitation at $475 \mathrm{~nm}$ ) or $508 \mathrm{~nm}$ (excitation at $395 \mathrm{~nm}$ ). The two emission peaks belong to two chemically distinct species of the chromophore, namely the anionic form or the neutral phenolate. Excellent summaries of GFP photophysics are provided in refs. ${ }^{15,42-43}$.

Here, we introduce an experimental strategy to screen for the effects of covalentlylinked photostabilizers on fluorescent proteins. For this, we recombinantly produced a double cysteine mutant (A206C/L221C, Figure S1) of alpha-GFP (F99S/M153T/V163A) ${ }^{44}$ for attachment of photostabilizer-maleimide conjugates. The cysteines did not influence the fluorescence parameters, i.e., spectrum and quantum yield, of the protein and also labelling with cylcooctatetraene (COT), trolox (TX) and a nitrophenyl-group showed negligible effects. Strikingly, we found a substantial increase of photostability upon conjugation to the azobenzene (AB) derivative, 4phenylazomaleinanil (4-PAM, Figure S1C). Although the mechanism underlying FPphotostabilization by azobenzene remains to be elucidated, our study paves the way towards the development and design of a second generation of fluorescent proteins with photostabilizers placed directly in the protein barrel by methods such as unnatural amino acid incorporation.

\section{Results}

A key obstacle in designing our research was the complex photophysical behavior of FPs, which meant that not only the properties of the chromophore itself, but also factors such as the ß-barrel structure/biochemical state and the specific environment of the proteins had to be considered ${ }^{45-48}$. Although unnatural amino-acid incorporation does present an attractive strategy for the introduction of a photostabilizer into an FP, this route seemed challenging due to low protein expression levels or incorrect protein folding. Therefore, we decided for a strategy where photostabilizers can be covalently linked to GFP via thiol-malemide chemistry (Figure 2A).

We produced a double cysteine mutant of $\alpha$-GFP, a GFP variant with mutations 
it additionally contains two solvent-accessible cysteine residues (A206C, L221C, Figure 2A). The side chains of A206 and L221 are directed to the outside of the Bbarrel, and therefore, following cysteine substitution of these residues, and labelling, photostabilizers can be placed outside of the barrel.
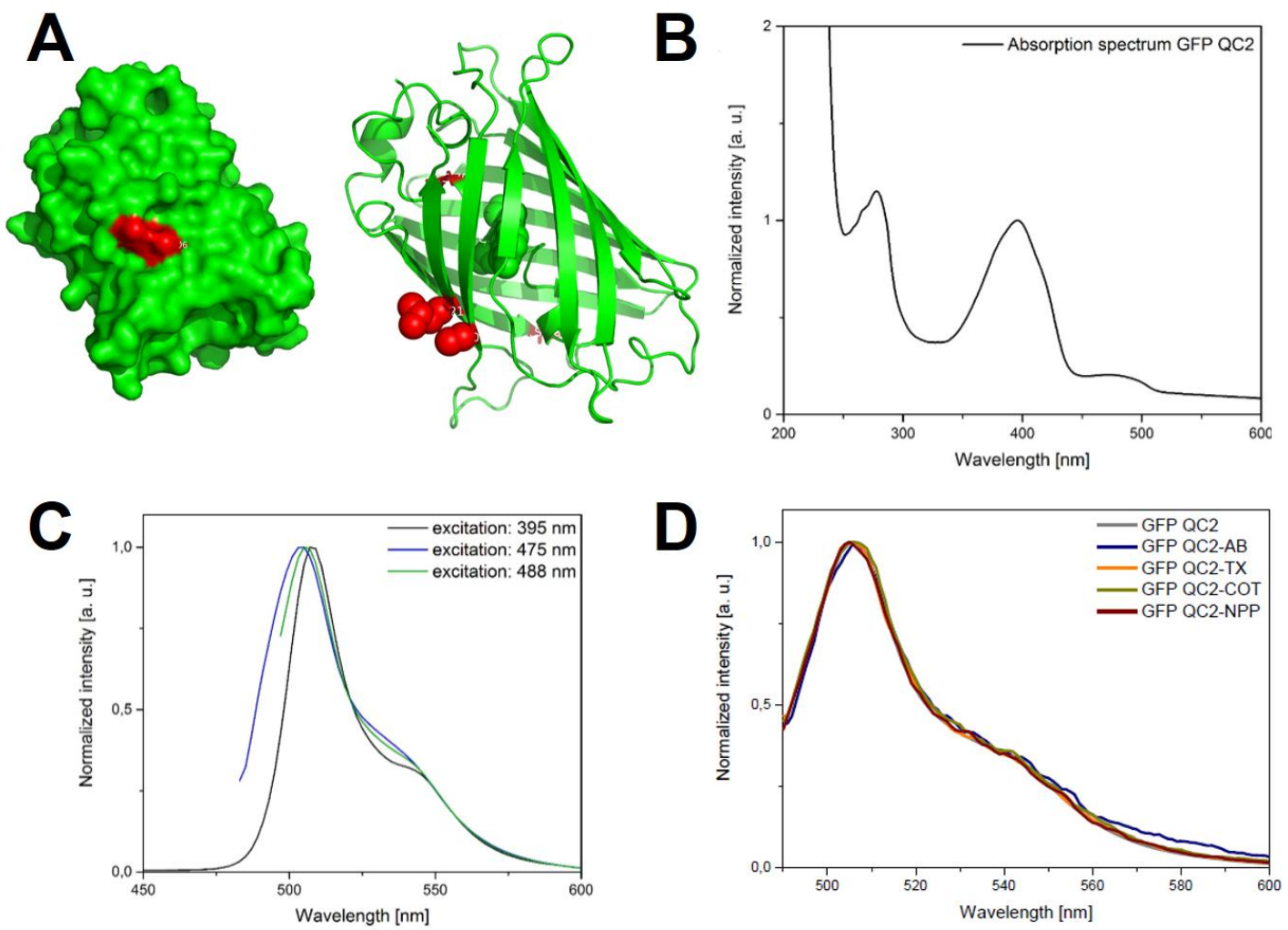

132

Figure 2. (A) Crystal structure of GFP-QC2 indicating residues $A 206$ and L221 in red. These residues were substituted with cysteines in this study for attachment of maleimide photostabilizers. (B) Absorbance and (C) emission spectra, and (D) normalized emission spectra of unlabeled and labeled GFP-QC2.

The idea was that A206C and L221C (Figure 2A) would be points of attachment for photostabilizers that can affect the chromophore via changes of the protein-barrel/9 or alternatively via triplet energy-transfer processes using long-lived triplet-states ${ }^{39}$. While the latter are believed to occur more likely via Dexter-processes ${ }^{22-23}$, which would require collisions between FP chromophore and photostabilizer, there is support that certain triplet quenchers might utilize a Förster mechanism ${ }^{50}$. We thus reasoned that intramolecular triplet-quenching in FPs might not strictly require direct contacts between chromophore and stabilizer but proximity. This idea is strongly supported by 
the observation that FPs can also be influenced by solution-based photostabilizers (Figure S2 and refs. ${ }^{51-53}$ ). Tinnefeld and co-workers also demonstrated that EYFP shows a 6-fold enhanced photostability when using dSTORM/ROXS-buffer, i.e., a reducing-oxidizing buffer cocktail, oxygen removal and thiol addition ${ }^{54}$.

$\alpha$-GFP contains two natural cysteines $(\mathrm{C} 48, \mathrm{C} 70)$ which may have potentially interfered with our desired labeling of the barrel using maleimide chemistry. C48 is solvent-accessible, but too far away from the chromophore itself to be useful for photostabilizer attachment and was therefore removed by substitution for a serine residue (Figure S1A). In contrast, C70 is not solvent-accessible in the folded form of GFP, and was therefore not expected to interfere with labeling (Figure S1B). The final construct GFP-QC2 was verified by sequencing to carry the following mutations: C48S/F99S/M153T/N163A/A206C/L221C (Material and Methods \& Figure S4).

The absorption and emission properties of GFP-QC2 were analyzed by steadystate spectroscopy methods ${ }^{27}$, and the results of these analysis are given in Figure 2/S3. The spectral characteristics of GFP-QC2 resembled those of $\alpha-G F P^{55}$. The absorption spectrum of GFP-QC2 shows a main peak at $2395 \mathrm{~nm}$ (neutral chromophore) and a smaller peak at $\sim 475 \mathrm{~nm}$ (anionic chromophore). In the UV range, absorbance by the aromatic amino acids tryptophan, tyrosine and phenylalanine, dominatedand dominate the absorption spectrum giving rise to an additional peak at $\sim 280 \mathrm{~nm}$. An important characteristic of the absorption spectrum was that the ratio of extinction coefficients of GFP-QC2 was slightly below $\sim 1$ at 280/395 nm.

Importantly, GFP-QC2 shows a fluorescence spectrum and quantum yield ${ }^{55}$ of $0.81 \pm 0.02$ (Figure S3) which resemble those of $\alpha$-GFP. Also the presence or absence of TCEP does not influence the spectra and quantum yield $(0.81 \pm 0.01)$, suggesting that cysteine oxidation or di-sulfide bridge formation does not occur in GFP-QC2. We also determined the quantum yield of eGFP to validate our method and found values of $0.63 \pm 0.02$ and $0.63 \pm 0.02$ in the absence and presence of TCEP, respectively (Figure S3). All this supports the idea that the cysteines A206C/L221C will provide anchor points for covalent attachment of photostabilizers, but do not influence the photophysics of the FP-chromophore, e.g., by modification of the barrel-structure. 
To test for intramolecular photostabilization, we compared the photophysical properties of unlabeled GFP-QC2 with labelled variants carrying the photostabilizers 4-PAM, Trolox (TX), cyclooctatetraene (COT) and nitrophenyl (NPP); see SI for details of photostabilizer synthesis. TX, COT and NPP are photostabilizers that have been extensively used in self-healing dyes due to their triplet-state energy matching with organic fluorophores for Dexter-transfer (COT) or photo-induced electron-transfer (TX, NPP). ${ }^{22-23,}{ }^{26-29}$ Azobenzene and stilbene, used in the original articles by Lüttke and coworkers for POPOP-dyes are both known as potent quenchers of triplet-states ${ }^{56}$. Since solution-quenching of triplet-states with rate constants up to $\sim 10^{10} \mathrm{M}^{-1} \mathrm{~s}^{-1}$ were observed using azobenzene ${ }^{56}$, this molecule is generally an interesting candidate for both intra- and intermolecular photostabilization. Reasons for not selecting azobenzene earlier on in the development of self-healing dyes may have been caused by its additional ability to induce phototriggered conformational changes (in biological structural such as proteins ${ }^{57-59}$ ), which require additional control experiments of biochemical function.

Labelling of GFP-QC2 was achieved using a protocol adapted from singlemolecule Förster resonance energy transfer experiments ${ }^{60}$ (details see SI: 2. Material and Methods). The labelling of GFP-azobenzene (GFP-AB) was monitored by size exclusion chromatography (Figure 3) via absorbance measurements at $280 \mathrm{~nm}$ (Trp/Tyr absorbance of GFP), 320 nm (4-PAM) and 395 nm (GFP chromophore). For GFP-QC2, the 280/395 ratio was just below 1 (Fig. 3A), whereas it was just above 1 for GFP-AB (Fig. 3B). These findings are consistent with the absorption spectrum of GFP-QC2 in Figure 2. A clear indication for labelling of GFP with the azobenzenederivative 4-PAM is an absorbance increase at $320 \mathrm{~nm}$ (Fig. 3A vs. 3B; see 4-PAM absorbance spectrum in Figure S1).

The procedure was repeated for the other three photostabilizers, although labelling could not be monitored by UVIVIS methods, because NPP, TX and COT show no characteristic absorbance at wavelengths $>300 \mathrm{~nm}$. Therefore, for these GFPphotostabilizer conjugates (GFP-COT, GFP-NPP, and GFP-TX), their spectroscopic characterization was performed using single-molecule TIRF (total internal reflection 
205 fluorescence) microscopy. The bulk emission spectra of unlabeled and all four labeled

with blue-shifted absorption spectra ${ }^{27,47}$.
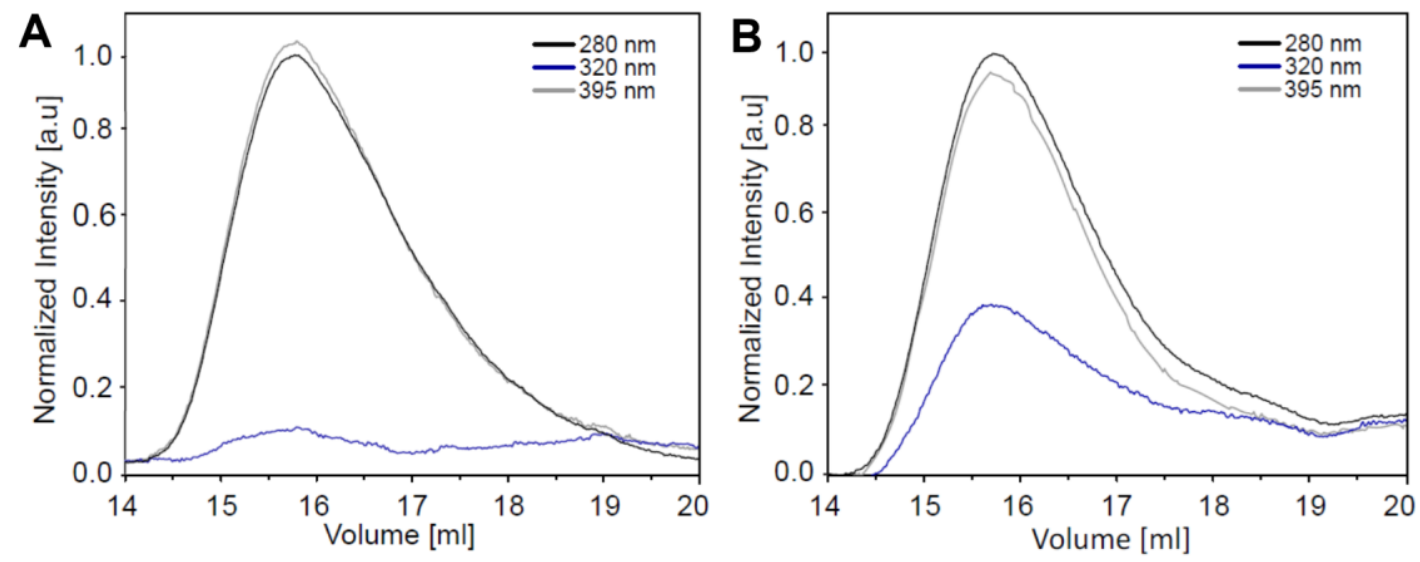

Figure 3. Size exclusion chromatograms of GFP-QC2 without (A) and with (B) 4-PAM showing an absorbance increase at $320 \mathrm{~nm}$ where PAM shows its maximum absorbance.

For single-molecule TIRF studies the proteins were immobilized on microscope coverslips according to published procedures ${ }^{34}$ (details see Material and methods). fluorescence spots in camera images (Figure 4A).
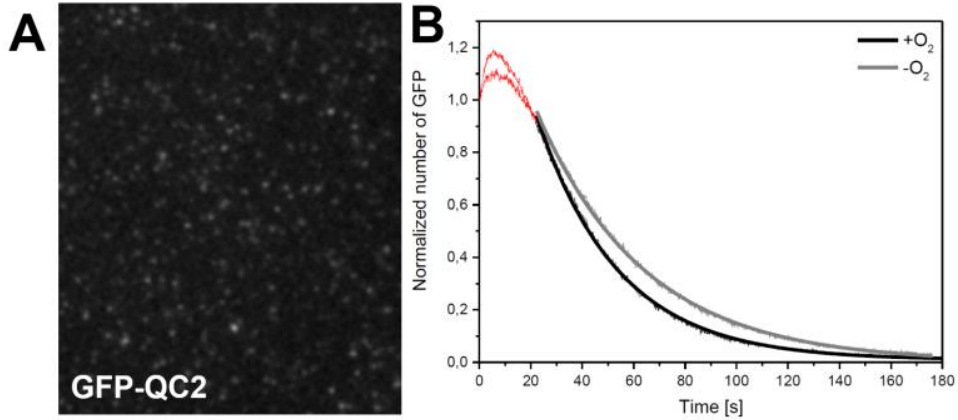

D
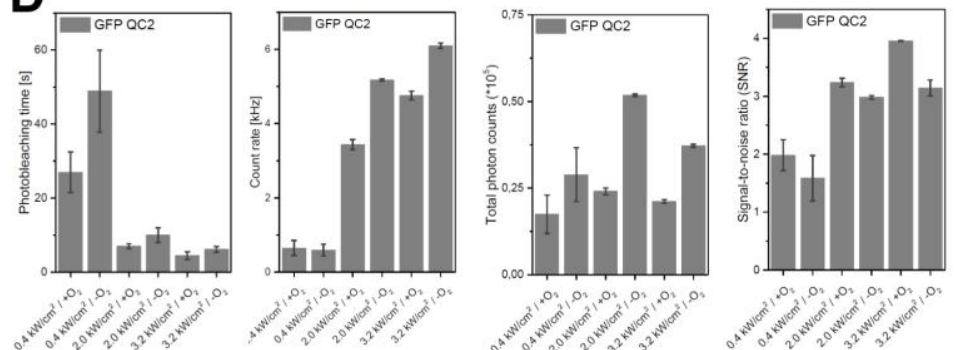
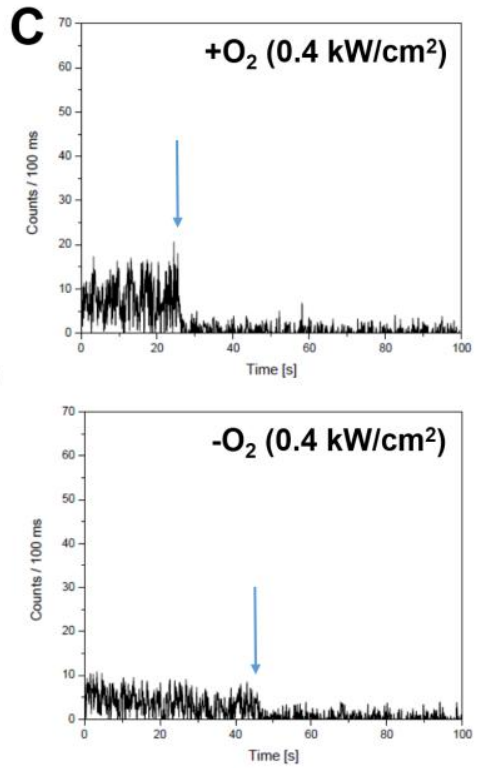

Figure 4. Quantitative photophysical characterization of GFP-QC2 in the presence and absence of oxygen under different excitation conditions following methods described in ref. ${ }^{34}$.

(A) TIRF image with (B) bleaching analysis counting fluorophore number per frame as a function of time.

(C) Fluorescent time 
traces of individual GFP-QC2 molecules (arrows indicate photobleaching) with (D) quantitative photophysical analysis under different excitation conditions. All experiments were repeated within independent biological repeats for at least three times. Bar graphs were derived from averages of $>5$ movies per conditions per repeat.

GFP-QC2 behaved similarly to other fluorescent proteins when studied on the single-molecule level featuring low photostability (Figure 4B), poor signal-to-noise ratio (SNR) and low brightness for both oxygenated and deoxygenated conditions (Figure 4C). Deoxygenated conditions can increase photon emission as oxygen is a fluorescence quencher or diminish them if reactive-oxygen mediates novel photobleaching pathways ${ }^{47,61-62}$. The analysis of spot numbers in each movie frame (Figure 4B) and fluorescence time trace analysis (Figure 4C/5) using previously published procedures ${ }^{34}$ allowed us to quantitatively determine the count-rate, SNR and photobleaching times for single molecules for different excitation intensities $(0.4,2.0$, $3.2 \mathrm{~kW} / \mathrm{cm}^{2}$ ) in the absence and presence of oxygen (Figure 4D). For unlabeled GFPQC2 fluorophores (Figure 4D), we observed short fluorescence periods of $\sim 20 \mathrm{~s}$ with count rates of $\sim 0.5 \mathrm{kHz}$ at $0.4 \mathrm{~kW} / \mathrm{cm}^{2}$ (see Figure 5 for individual traces). The SNR of GFP-QC2 at 100 ms binning was between 1.5-4 (Figure 4D).
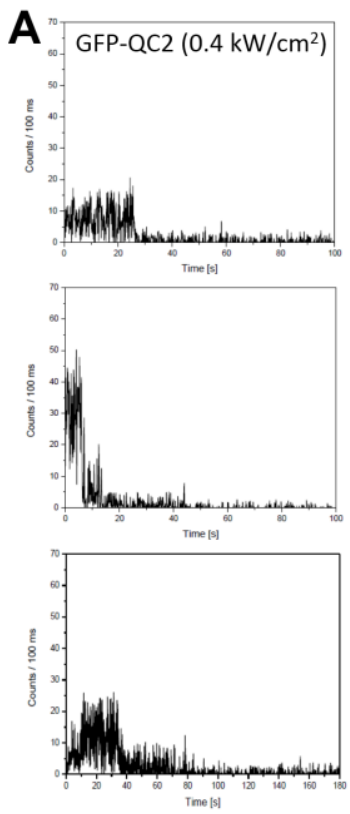
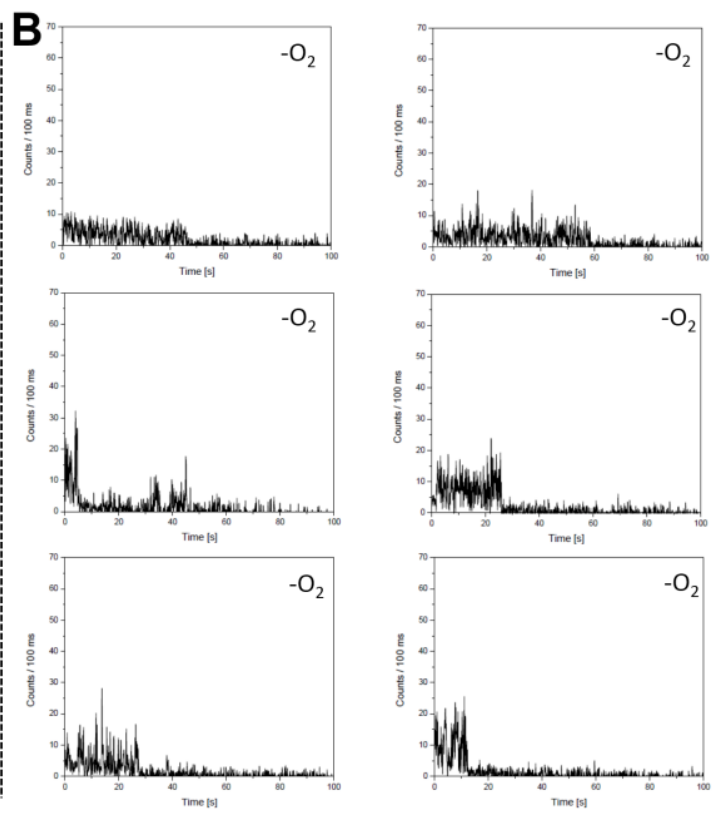

Figure 5. TIRF time traces of GFP-QC2 (A) in the presence and (B) in the absence of oxygen at 0.4 $\mathrm{kW} / \mathrm{cm}^{2}$ excitation intensity.

The total number of detected photons were similar for most excitation conditions, 
i.e., between $\sim 25000-50000$. The constant values resulted from faster photobleaching but higher count-rate for increasing excitation intensity (Figure 4D). The normalized number of GFP-QC2 proteins per frame always showed an initial increase in the first $5-10 \mathrm{~s}$ that is consistent with previous reports of GFP/ $\alpha$-GFP and relates to photoconversion proesses (Figure 4B and ref. ${ }^{55}$ ). We thus analyzed photobleaching times via an exponential fit of the tail of the decay. We also studied the influence of known solution additives such as COT and TX as controls (Figure S2). These experiments were done before we started our study on the intramolecular stabilizers to verify previous reports ${ }^{51-53}$ that solution additives (and thus potentially also molecules attached outside the ß-barrel) can influence the GFP-chromophore. For addition of both TX and COT, we found negative impacts on photobleaching rates, increased count-rate and constant total detected photons/SNR for single-immobilized GFP-QC2 molecules (Figure S2). Following these investigations, we tested covalent linkage of photostabilizers to the residues A206C and L221C (Figure 6).
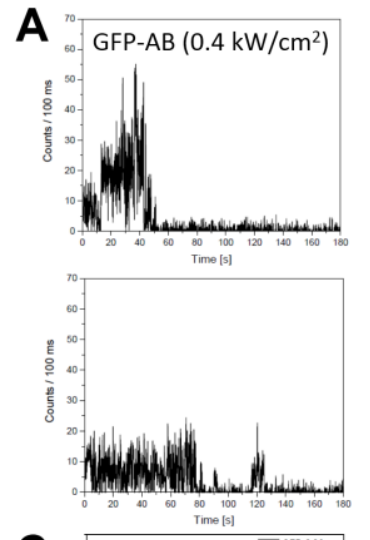

C

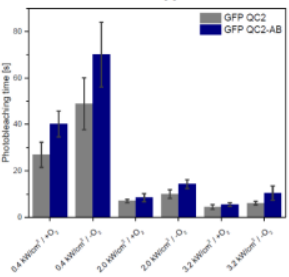

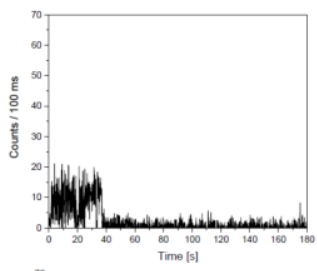
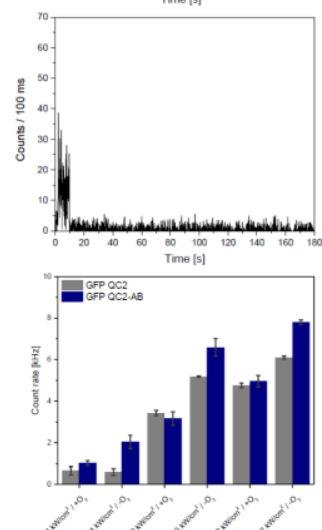

B
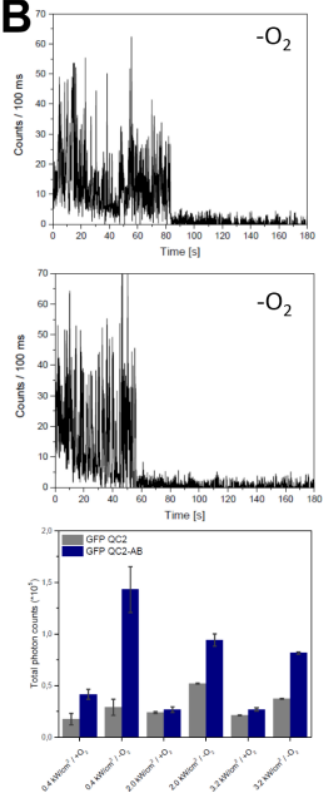
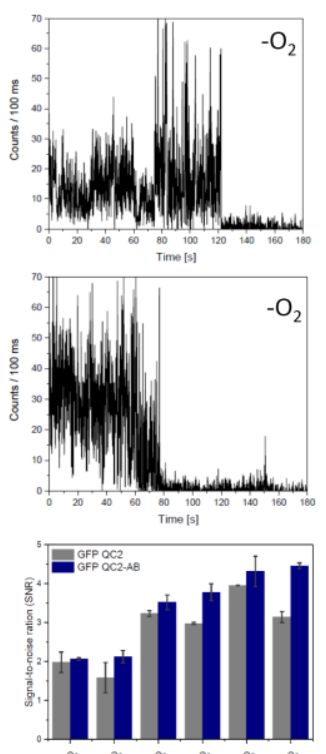

Figure 6. TIRF time traces of GFP-AB (A) in the presence and (B) in the absence of oxygen at $0.4 \mathrm{~kW} / \mathrm{cm}^{2}$ excitation intensity. (C) Quantitative photophysical analysis of GFP-AB under different excitation conditions.

The selected photophysical parameters were improved by conjugation of 4-PAM to GFP-QC2, referred to as GFP-AB (Figure 6). Photobleaching was retarded by 4PAM for all conditions (Figure 6C), but most significantly in the absence of oxygen. 
Increases in the count-rate by $A B$ were only observed in the absence of oxygen. SNR

changes were found to be non-systematic. Strikingly, the increases of both count-rate and photobleaching time gave rise to a substantial gain in the total number of observed photons before photobleaching for all excitation conditions, especially in the absence of oxygen (Figure 6C).

As outlined before, the barrel of GFP-QC2 was also labeled with the photostabilizers TX, NPP, and COT to generate GFP-TX, GFP-NPA, GFP-COT, respectively (Figure 7); see SI for synthesis of photostabilizer maleimides and the labelling procedure.
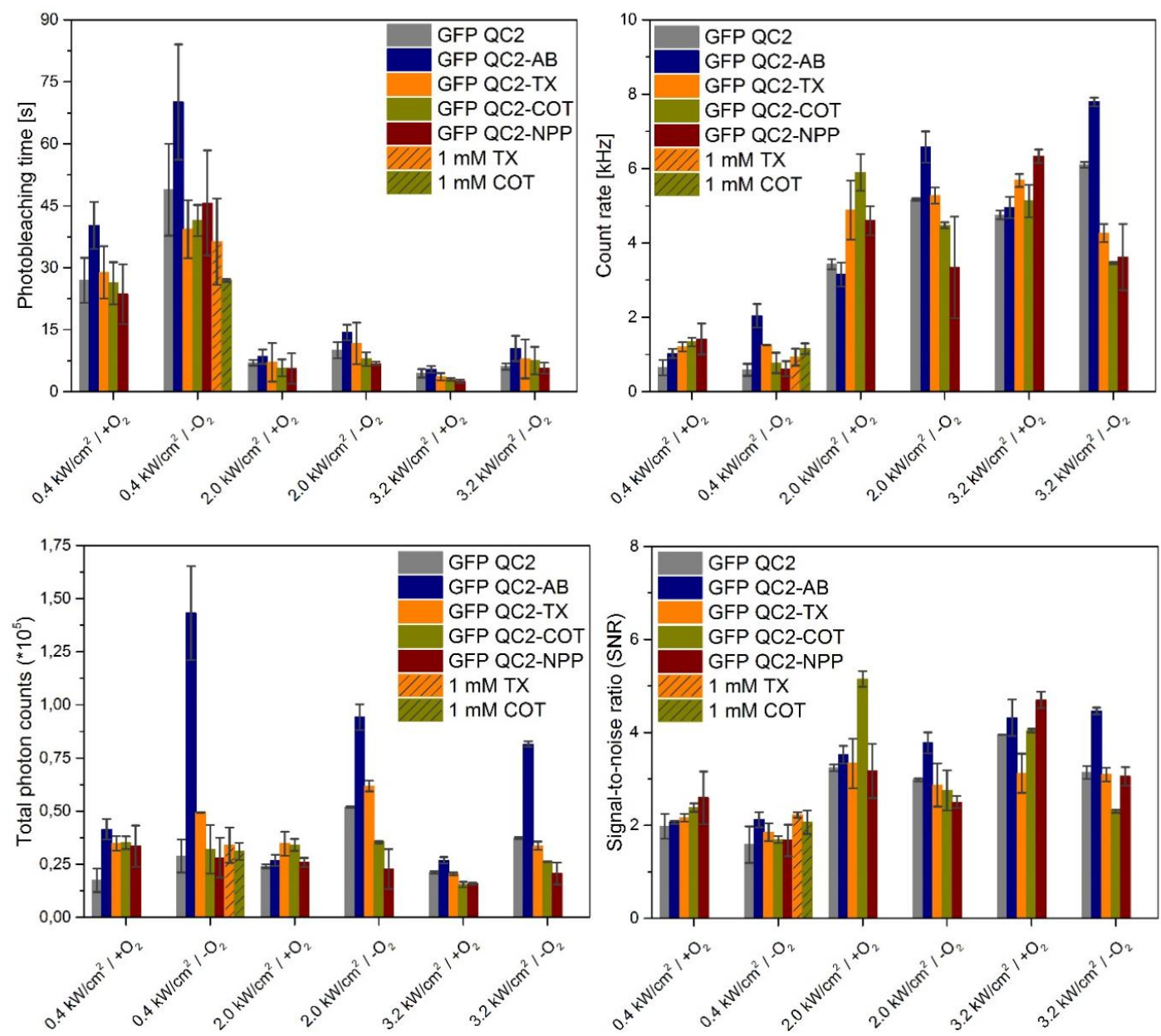

Figure 7: Quantitative photophysical characterization of GFP-QC2 with and without different photostabilizers in the presence and absence of oxygen at under different excitation conditions.

These experiments revealed only minor effects of the different stabilizers on the photophysical behavior of GFP-QC2 in contrast to 4-PAM. None of these other 
bioRxiv preprint doi https:/doi org/10 1101/2020 03.07.980722: this version posted March 7,2020 The copyright holder for this preprint (which was not certified by peer review) is the author/funder. All rights reserved. No reuse allowed without permission.

photostabilizers increased or decreased the photobleaching time, count-rate, total photon count and SNR strongly. Trolox showed some exceptions of this general statement with elevated count-rates at $2 \mathrm{~kW} / \mathrm{cm}^{2}$.

The observed small effects of TX, NPP, and COT were on one hand disappointing, albeit not surprising since other blue fluorophores $\left(\mathrm{Cy} 2^{22}\right.$, fluoresceins $\left.{ }^{36}\right)$ were shown to be only minimally affected by these stabilizers. Importantly, these data further support that the idea of a unique photophysical interaction between the FPchromophore and 4-PAM, which was not seen with any other stabilizer.

\section{Summary and Discussion}

In this study, we showed that a mutant GFP with two specific cysteine (A206/L221C) residues available for labelling with commercial and custom-made maleimidephotostabilizers, exhibited increased photostability upon conjugation to the azobenzene derivative 4-PAM (abbreviated GFP-AB). It could, however, not be shown that the underlying mechanism for this improvement is related to triplet-state quenching. Exactly this was demonstrated to be true for the class of self-healing dyes, which feature similar covalent linkage of photostabilizers to fluorophores ${ }^{28}$. The observed positive impact of 4-PAM on GFP photostability and the long recently determined triplet-state lifetimes of $\mathrm{FPs}^{39}$, however, supports the idea that FPs may be usefully targeted by intramolecular photostabilization, which provides an alternative approach to previous FP-improvement strategies using e.g., chromophore fluorination ${ }^{63}$.

While our study paves the way for a systematic investigations of how to equip GFPs with suitable intramolecular photostabilizers, there are several issues that require further attention. The strategy to label GFP on the outside of the ß-barrel may reduce efficient interaction between the chromophore and the photostabilizer. While, there is convincing published evidence that the $ß$-barrel does not shield the FPchromophore fully ${ }^{51-53}$ from interacting molecules in the buffer and also that tripletquenching proesses might be mediated by a contact-less Förster mechanisms ${ }^{50}$, we speculate that selecting a residue inside the ß-barrel might be even more promising. 


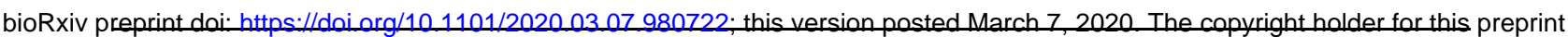
(which was not certified by peer review) is the author/funder. All rights reserved. No reuse allowed without permission.

311 This could be done with residues such as C70 or other selected positions. In this case,

312 a modified labelling strategy would be required, where the GFP is immobilized for labelling, unfolded to make the internal residue accessible and refolded after labelling has occurred.

Ultimately, a major point of discussion is the type of photostabilizer and quenching mechanism (PET vs. energy transfer) required to successfully stabilize GFP. As for a number of blue-absorbing fluorophores (Cy2 or fluorescein), the common quenchers TX, NPP and COT were also ineffective for GFP. Fluorescein and other blue dyes have a triplet energy of $1.98 \mathrm{eV}$, which is much higher than those found for green- and redemitting dyes with values between $1.46 \mathrm{eV}\left(\right.$ ATTO647N) and $1.72 \mathrm{eV}(\mathrm{TMR})^{36}$. The triplet-state of GFP was recently characterized and found to have a surprisingly low energy in the range of $\sim 1.4 \mathrm{eV} .^{39}$ This finding is not fully consistent with the fact that COT remains ineffective for GFP-QC2, since COT is very effective for ATTO647N, which has a similar triplet-state energy as GFP. Generally, for blue fluorophores alternative quenchers with energetically higher-lying triplet-states such azobenzene $\left(\sim 2 \mathrm{eV}^{56}\right)$, stilbene $\left(\sim 2.4 \mathrm{eV}^{64}\right)$ might be more optimal, also as solution additive for dyes with absorbance in the near-UV and blue spectral range.

\section{Acknowledgment}

This work was financed by an ERC Starting Grant (No. 638536 - SM-IMPORT to T.C.) and Deutsche Forschungsgemeinschaft (SFB863 project A13 \& GRK2062 project C03 to T.C. and JU650/2-2 to G.J.). L. Zhang thanks the Alexander von Humboldt foundation for a postdoctoral research fellowship. J.H.M.vdV. acknowledges UbboEmmius funding (University of Groningen). T.C. was further supported by Deutsche Forschungsgemeinschaft through the cluster of excellence CiPSM and by the Center of Nanoscience Munich (CeNS). We thank D. A. Griffith for sequencing of the GFPQC2 plasmid, reading of the manuscript and thoughtful comments and suggestions. project. 


\section{References}

342 1. Chalfie, M.; Tu, Y.; Euskirchen, G.; Ward, W. W.; Prasher, D. C., Green Fluorescent 343 Protein as a Marker for Gene Expression. Science 1994, 263, 802-805.

2. Heim, R.; Prasher, D. C.; Tsien, R. Y., Wavelength Mutations and Posttranslational Autoxidation of Green Fluorescent Protein. Proceedings of the National Academy of Sciences 1994, 91, 12501-12504.

3. Harms, G. S.; Cognet, L.; Lommerse, P. H.; Blab, G. A.; Schmidt, T., Autofluorescent Proteins in Single-Molecule Research: Applications to Live Cell Imaging Microscopy. Biophysical journal 2001, 80, 2396-2408.

4. Ormö, M.; Cubitt, A. B.; Kallio, K.; Gross, L. A.; Tsien, R. Y.; Remington, S. J., Crystal Structure of the Aequorea Victoria Green Fluorescent Protein. Science 1996, 273, 1392-1395.

5. Shimomura, O.; Johnson, F. H.; Saiga, Y., Extraction, Purification and Properties of Aequorin, a Bioluminescent Protein from the Luminous Hydromedusan, Aequorea. Journal of cellular and comparative physiology 1962, 59, 223-239.

6. Crivat, G.; Taraska, J. W., Imaging Proteins inside Cells with Fluorescent Tags. Trends in biotechnology 2012, 30, 8-16.

7. Cranfill, P. J.; Sell, B. R.; Baird, M. A.; Allen, J. R.; Lavagnino, Z.; De Gruiter, H. M.; Kremers, G.-J.; Davidson, M. W.; Ustione, A.; Piston, D. W., Quantitative Assessment of Fluorescent Proteins. Nature methods 2016, 13, 557.

8. Jung, G.; Zumbusch, A., Improving Autofluorescent Proteins: Comparative Studies of the Effective Brightness of Green Fluorescent Protein (Gfp) Mutants. Microscopy research and technique 2006, 69, 175-185.

9. Toseland, C. P., Fluorescent Labeling and Modification of Proteins. Journal of chemical biology 2013, 6, 85-95. Noninvasive Imaging of Quantum Dots in Mice. Bioconjugate chemistry 2004, 15, 7986. Nanocrystals as Fluorescent Biological Labels. science 1998, 281, 2013-2016. Fluorescent Proteins at a Glance. Journal of cell science 2011, 124, 157-160.

13. Bae, J. H.; Rubini, M.; Jung, G.; Wiegand, G.; Seifert, M. H.; Azim, M. K.; Kim, J.S.; Zumbusch, A.; Holak, T. A.; Moroder, L., Expansion of the Genetic Code Enables Design of a Novel "Gold" Class of Green Fluorescent Proteins. Journal of molecular biology 2003, 328, 1071-1081. 
15. Zimmer, M., Green Fluorescent Protein (Gfp): Applications, Structure, and Related Photophysical Behavior. Chemical reviews 2002, 102, 759-782.

16. Andrews, B. T.; Schoenfish, A. R.; Roy, M.; Waldo, G.; Jennings, P. A., The Rough Energy Landscape of Superfolder Gfp Is Linked to the Chromophore. Journal of molecular biology 2007, 373, 476-490.

17. Pédelacq, J.-D.; Cabantous, S.; Tran, T.; Terwilliger, T. C.; Waldo, G. S., Engineering and Characterization of a Superfolder Green Fluorescent Protein. Nature biotechnology 2006, 24, 79-88.

18. Brakemann, T.; Stiel, A., Weber G, Andresen M, Testa I, Grotjohann T, Leutenegger M, Plessmann U, Urlaub H, Eggeling C, Wahl Mc, Hell Sw, Jakobs S (2011) a Reversibly Photoswitchable Gfp-Like Protein with Fluorescence Excitation Decoupled from Switching. Nat Biotechnol, 29, 942-947.

19. Shaner, N. C.; Lambert, G. G.; Chammas, A.; Ni, Y.; Cranfill, P. J.; Baird, M. A.; Sell, B. R.; Allen, J. R.; Day, R. N.; Israelsson, M., A Bright Monomeric Green Fluorescent Protein Derived from Branchiostoma Lanceolatum. Nature methods 2013, 10, 407.

20. Dedecker, P.; De Schryver, F. C.; Hofkens, J., Fluorescent Proteins: Shine on, You Crazy Diamond. Journal of the American Chemical Society 2013, 135, 2387-2402.

21. Kneen, M.; Farinas, J.; Li, Y.; Verkman, A., Green Fluorescent Protein as a Noninvasive Intracellular Ph Indicator. Biophysical journal 1998, 74, 1591-1599.

22. Altman, R. B.; Zheng, Q.; Zhou, Z.; Terry, D. S.; Warren, J. D.; Blanchard, S. C., Enhanced Photostability of Cyanine Fluorophores across the Visible Spectrum. Nature methods 2012, 9, 428-429.

23. van der Velde, J. H.; Ploetz, E.; Hiermaier, M.; Oelerich, J.; de Vries, J. W.; Roelfes, G.; Cordes, T., Mechanism of Intramolecular Photostabilization in Self-Healing Cyanine Fluorophores. ChemPhysChem 2013, 14, 4084-4093.

24. Liphardt, B., Laser Dyes with Intramolecular Triplet Quenching. 1981.

25. Liphardt, B.; Liphardt, B.; Lüttke, W., Laser Dyes lii: Concepts to Increase the Photostability of Laser Dyes. Optics communications 1983, 48, 129-133.

26. Dave, R.; Terry, D. S.; Munro, J. B.; Blanchard, S. C., Mitigating Unwanted Photophysical Processes for Improved Single-Molecule Fluorescence Imaging. Biophysical journal 2009, 96, 2371-2381.

27. Van Der Velde, J. H.; Oelerich, J.; Huang, J.; Smit, J. H.; Jazi, A. A.; Galiani, S.; Kolmakov, K.; Gouridis, G.; Eggeling, C.; Herrmann, A., A Simple and Versatile Design Concept for Fluorophore Derivatives with Intramolecular Photostabilization. Nature communications 2016, 7, 10144.

28. Zheng, Q.; Jockusch, S.; Zhou, Z.; Altman, R. B.; Warren, J. D.; Turro, N. J.; Blanchard, S. C., On the Mechanisms of Cyanine Fluorophore Photostabilization. The journal of physical chemistry letters 2012, 3, 2200-2203. 
29. Zheng, Q.; Juette, M. F.; Jockusch, S.; Wasserman, M. R.; Zhou, Z.; Altman, R. B.; Blanchard, S. C., Ultra-Stable Organic Fluorophores for Single-Molecule Research. Chemical Society Reviews 2014, 43, 1044-1056.

30. Zheng, Q.; Jockusch, S.; Zhou, Z.; Altman, R. B.; Zhao, H.; Asher, W.; Holsey, M.; Mathiasen, S.; Geggier, P.; Javitch, J. A., Electronic Tuning of Self-Healing Fluorophores for Live-Cell and Single-Molecule Imaging. Chemical science 2017, 8, 755-762.

31. Glembockyte, V.; Cosa, G., Redox-Based Photostabilizing Agents in Fluorescence Imaging: The Hidden Role of Intersystem Crossing in Geminate Radical Ion Pairs. Journal of the American Chemical Society 2017, 139, 13227-13233.

32. Tinnefeld, P.; Cordes, T., 'Self-Healing'dyes: Intramolecular Stabilization of Organic Fluorophores. Nature methods 2012, 9, 426.

33. Smit, J. H.; van der Velde, J. H.; Huang, J.; Trauschke, V.; Henrikus, S. S.; Chen, S.; Eleftheriadis, N.; Warszawik, E. M.; Herrmann, A.; Cordes, T., On the Impact of Competing Intra-and Intermolecular Triplet-State Quenching on Photobleaching and Photoswitching Kinetics of Organic Fluorophores. Physical Chemistry Chemical Physics 2019, 21, 3721-3733.

34. van der Velde, J. H.; Oelerich, J.; Huang, J.; Smit, J. H.; Hiermaier, M.; Ploetz, E.; Herrmann, A.; Roelfes, G.; Cordes, T., The Power of Two: Covalent Coupling of Photostabilizers for Fluorescence Applications. The journal of physical chemistry letters 2014, 5, 3792-3798.

35. van der Velde, J. H.; Uusitalo, J. J.; Ugen, L.-J.; Warszawik, E. M.; Herrmann, A.; Marrink, S. J.; Cordes, T., Intramolecular Photostabilization Via Triplet-State Quenching: Design Principles to Make Organic Fluorophores "Self-Healing". Faraday discussions 2015, 184, 221-235.

36. Zheng, Q.; Jockusch, S.; Rodríguez-Calero, G. G.; Zhou, Z.; Zhao, H.; Altman, R. B.; Abruña, H. D.; Blanchard, S. C., Intra-Molecular Triplet Energy Transfer Is a General Approach to Improve Organic Fluorophore Photostability. Photochemical \& photobiological sciences 2016, 15, 196-203.

37. Van Der Velde, J. H.; Smit, J. H.; Hebisch, E.; Punter, M.; Cordes, T., Self-Healing Dyes for Super-Resolution Fluorescence Microscopy. Journal of Physics D: Applied Physics 2018, 52, 034001.

38. Sirbu, D.; Woodford, O. J.; Benniston, A. C.; Harriman, A., Photocatalysis and SelfCatalyzed Photobleaching with Covalently-Linked Chromophore-Quencher Conjugates Built around Bophy. Photochemical \& Photobiological Sciences 2018, 17, 750-762.

39. Byrdin, M.; Duan, C.; Bourgeois, D.; Brettel, K., A Long-Lived Triplet State Is the Entrance Gateway to Oxidative Photochemistry in Green Fluorescent Proteins. Journal of the American Chemical Society 2018, 140, 2897-2905.

40. Yang, F.; Moss, L. G.; Phillips, G. N., The Molecular Structure of Green Fluorescent 
Protein. Nature biotechnology 1996, 14, 1246-1251.

41. Craggs, T. D., Green Fluorescent Protein: Structure, Folding and Chromophore Maturation. Chemical Society Reviews 2009, 38, 2865-2875.

42. Cui, G.; Lan, Z.; Thiel, W., Intramolecular Hydrogen Bonding Plays a Crucial Role in the Photophysics and Photochemistry of the Gfp Chromophore. Journal of the American Chemical Society 2012, 134, 1662-1672.

43. Remington, S. J., Fluorescent Proteins: Maturation, Photochemistry and Photophysics. Current opinion in structural biology 2006, 16, 714-721.

44. Crameri, A.; Whitehorn, E. A.; Tate, E.; Stemmer, W. P., Improved Green Fluorescent Protein by Molecular Evolution Using DNA Shuffling. Nature biotechnology 1996, 14, 315-319.

45. Chen, H.; Ahsan, S. S.; Santiago-Berrios, M. E. B.; Abruña, H. D.; Webb, W. W., Mechanisms of Quenching of Alexa Fluorophores by Natural Amino Acids. Journal of the American Chemical Society 2010, 132, 7244-7245.

46. Chen, H.; Rhoades, E.; Butler, J. S.; Loh, S. N.; Webb, W. W., Dynamics of Equilibrium Structural Fluctuations of Apomyoglobin Measured by Fluorescence Correlation Spectroscopy. Proceedings of the National Academy of Sciences 2007, 104, 10459-10464.

47. Lakowicz, J. R., Principles of Fluorescence Spectroscopy; Springer Science \& Business Media, 2013.

48. Vaiana, A. C.; Neuweiler, H.; Schulz, A.; Wolfrum, J.; Sauer, M.; Smith, J. C., Fluorescence Quenching of Dyes by Tryptophan: Interactions at Atomic Detail from Combination of Experiment and Computer Simulation. Journal of the American Chemical Society 2003, 125, 14564-14572.

49. Mamontova, A.; Grigoryev, A.; Tsarkova, A.; Lukyanov, K.; Bogdanov, A., Struggle for Photostability: Bleaching Mechanisms of Fluorescent Proteins. Russian Journal of Bioorganic Chemistry 2017, 43, 625-633.

50. Schaefer, F.; Zhang, F.-G.; Jethwa, J., Intramolecular Tt-Energy Transfer in Bifluorophoric Laser Dyes. Applied Physics B 1982, 28, 37-41.

51. Bogdanov, A. M.; Kudryavtseva, E. I.; Lukyanov, K. A., Anti-Fading Media for Live Cell Gfp Imaging. PloS one 2012, 7.

52. Bogdanov, A. M.; Mishin, A. S.; Yampolsky, I. V.; Belousov, V. V.; Chudakov, D. M.; Subach, F. V.; Verkhusha, V. V.; Lukyanov, S.; Lukyanov, K. A., Green Fluorescent Proteins Are Light-Induced Electron Donors. Nature chemical biology 2009, 5, 459.

53. Saha, R.; Verma, P. K.; Rakshit, S.; Saha, S.; Mayor, S.; Pal, S. K., Light Driven Ultrafast Electron Transfer in Oxidative Redding of Green Fluorescent Proteins. Scientific reports 2013, 3, 1-7.

54. Jusuk, I.; Vietz, C.; Raab, M.; Dammeyer, T.; Tinnefeld, P., Super-Resolution Imaging Conditions for Enhanced Yellow Fluorescent Protein (Eyfp) Demonstrated on 
DNA Origami Nanorulers. Scientific reports 2015, 5, 14075.

55. Patterson, G. H.; Knobel, S. M.; Sharif, W. D.; Kain, S. R.; Piston, D. W., Use of the Green Fluorescent Protein and Its Mutants in Quantitative Fluorescence Microscopy. Biophysical journal 1997, 73, 2782.

56. Monti, S.; Gardini, E.; Bortolus, P.; Amouyal, E., The Triplet State of Azobenzene. Chemical Physics Letters 1981, 77, 115-119.

57. Cordes, T.; Weinrich, D.; Kempa, S.; Riesselmann, K.; Herre, S.; Hoppmann, C.; Rück-Braun, K.; Zinth, W., Hemithioindigo-Based Photoswitches as Ultrafast Light Trigger in Chromopeptides. Chemical physics letters 2006, 428, 167-173.

58. Ritterson, R. S.; Hoersch, D.; Barlow, K. A.; Kortemme, T., Design of LightControlled Protein Conformations and Functions. In Computational Design of Ligand Binding Proteins, Springer: 2016; pp 197-211.

59. Schrader, T. E.; Schreier, W. J.; Cordes, T.; Koller, F. O.; Babitzki, G.; Denschlag, R.; Renner, C.; Löweneck, M.; Dong, S.-L.; Moroder, L., Light-Triggered B-Hairpin Folding and Unfolding. Proceedings of the National Academy of Sciences 2007, 104, 15729-15734.

60. Gouridis, G.; Schuurman-Wolters, G. K.; Ploetz, E.; Husada, F.; Vietrov, R.; De Boer, M.; Cordes, T.; Poolman, B., Conformational Dynamics in Substrate-Binding Domains Influences Transport in the Abc Importer GInpq. Nature Structural \& Molecular Biology 2015, 22, 57.

61. Aitken, C. E.; Marshall, R. A.; Puglisi, J. D., An Oxygen Scavenging System for Improvement of Dye Stability in Single-Molecule Fluorescence Experiments. Biophysical journal 2008, 94, 1826-1835.

62. Benesch, R. E.; Benesch, R., Enzymatic Removal of Oxygen for Polarography and Related Methods. Science 1953, 118, 447-448.

63. Veettil, S.; Budisa, N.; Jung, G., Photostability of Green and Yellow Fluorescent Proteins with Fluorinated Chromophores, Investigated by Fluorescence Correlation Spectroscopy. Biophysical chemistry 2008, 136, 38-43.

64. Saltiel, J.; Chang, D.; Megarity, E.; Rousseau, A.; Shannon, P.; Thomas, B.; Uriarte, A., The Triplet State in Stilbene Cis-Trans Photoisomerization. Pure and Applied Chemistry 1975, 41, 559-579. 


\section{Supplementary information for: Characterization of fluorescent proteins with intramolecular photostabilization}

\section{Additional data and images}

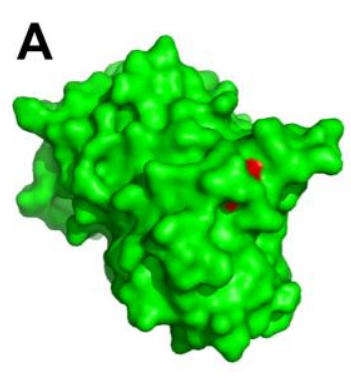

B

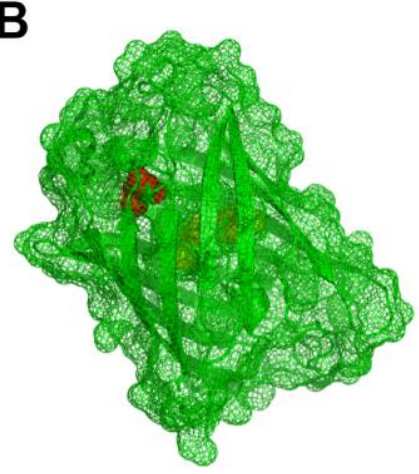

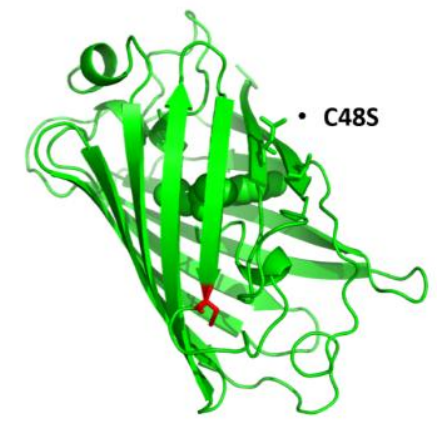
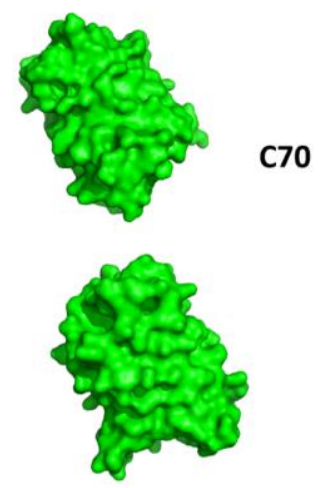

C<smiles>O=C1C=CC(=O)N1c1ccc(/N=N/c2ccccc2)cc1</smiles>

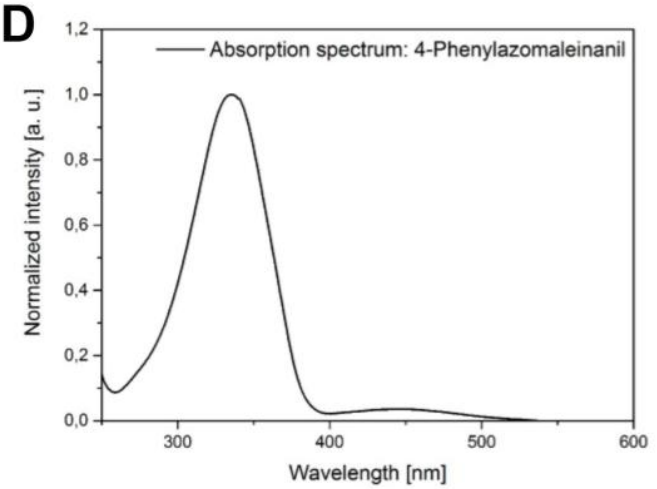

Figure S1: Crystal structures of GFP marking the location of (A) serine 48 (point mutation C48S, red) and (B) cysteine 70 (red). C48S is too far away from the chromophore and was thus deleted while C70 is not solventaccessible in the folded form of GFP rendering both poor candidates for labelling of GFP with photostabilizers in the folded form of the protein. (C) Absorbance spectrum (D) and chemical structure of 4-phenylazomaleinanil (4PAM) used for labelling of cysteine residues.
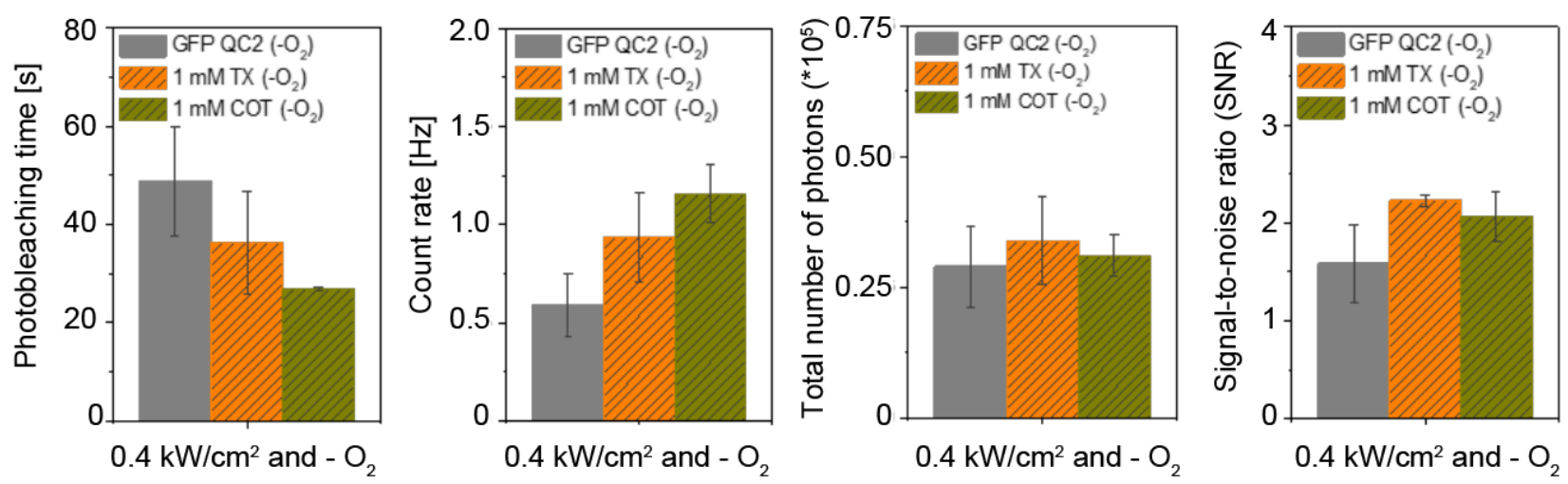

Figure S2: Photophysical properties of GFP-QC2 in different buffer environments in the absence of oxygen: no photostabilizer (grey), $1 \mathrm{mM}$ TX (yellow) and $1 \mathrm{mM} \mathrm{COT} \mathrm{(green).}$ 
A

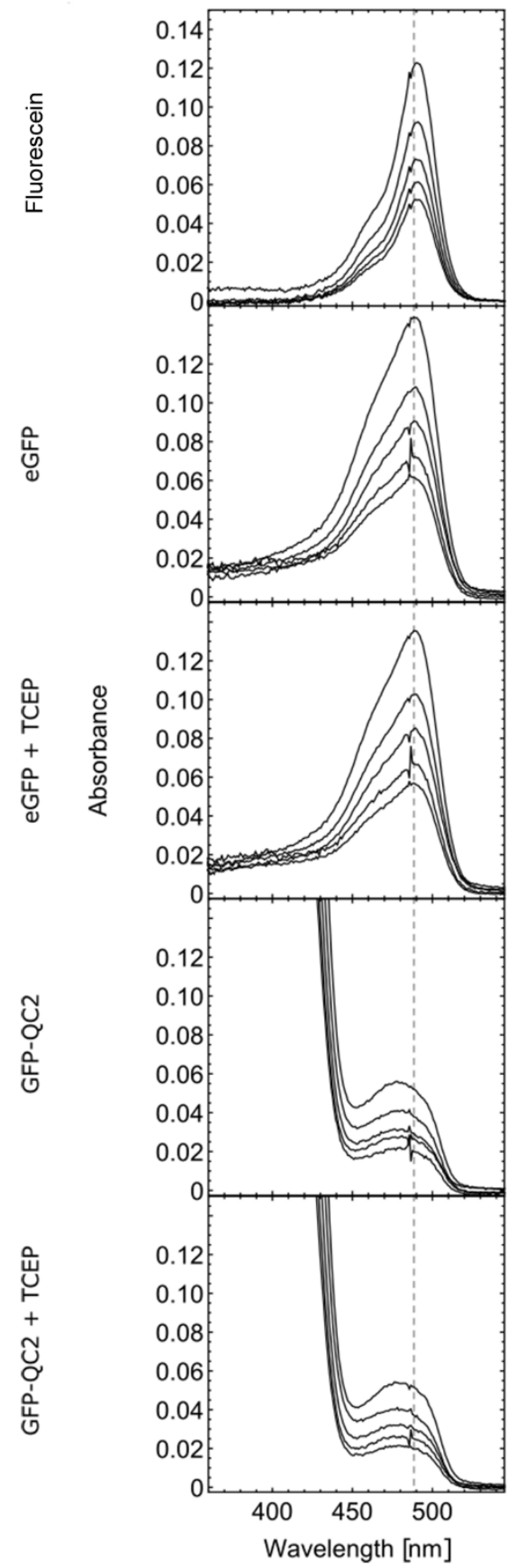

B

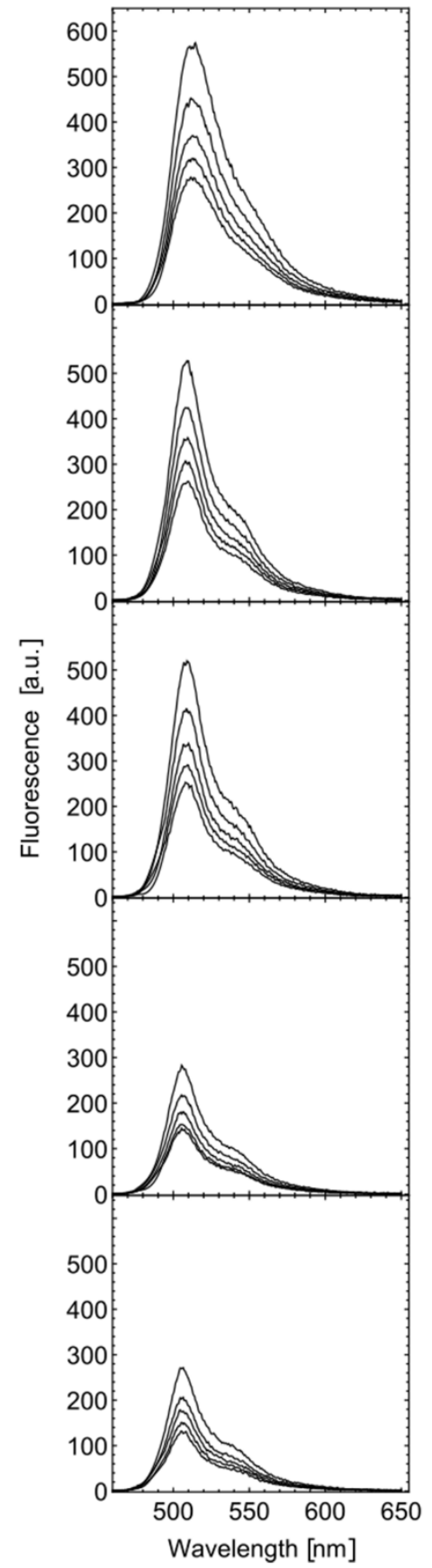

C

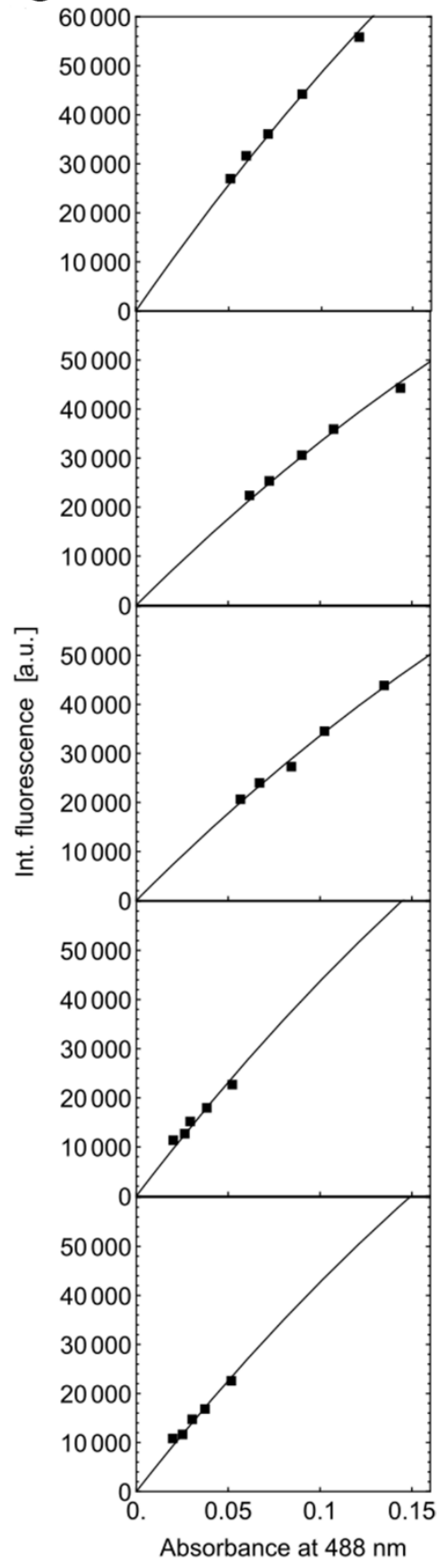

Figure S3: Quantum yield determination of eGFP and GFP-QC2 using fluorescein as standard. (A) Absorbance spectra with marked line at $488 \mathrm{~nm},($ B) emission spectra from excitation at $488 \mathrm{~nm}$, and (C) integrated emission spectrum from (B) versus the absorbance at $488 \mathrm{~nm}$ from (A) with fitted curve $m A_{488} \cdot 10^{-\frac{A_{488}}{2}}$ for Fluorescein, eGFP (without and with $1 \mathrm{mM}$ TCEP), and GFP-QC2 (without and with 1mM TCEP) (top to bottom). All measurements were done at 5 different concentrations. eGFP at $0.67,0.50,0.40,0.33$ and $0.29 \mathrm{mg} \mathrm{mL}^{-1}$ concentration, GFP-QC2 at $0.93,0.69,0.56,0.46$ and $0.40 \mathrm{mg} \mathrm{mL}^{-1}$ concentration, and fluorescein at 1.75, 1.31, 1.04, $0.87,0.74 \mu \mathrm{M}$ concentration. 
bioRxiv preprint doi: https://doi.org/10.1101/2020.03.07.980722; this version posted March 7, 2020. The copyright holder for this preprint (which was not certified by peer review) is the author/funder. All rights reserved. No reuse allowed without permission.

\section{Material and Methods}

For all methods described below, chemicals and conjugates from the companies Sigma-Aldrich, Merck KGaA, Roche Diagnostics GmbH, J. T. Baker, abcr GmbH, Laysan Bio, Qiagen and Macron Fine Chemicals were used without further purification.

\section{Overexpression and purification of GFP-QC2}

The GFP variant used here, as a starting point for the construction of GFP-QC2, was the Stemmer cycle 3 mutant or $\alpha$ GFP (F99S/M153T/V163A) ${ }^{1}$. The $\alpha$ GFP gene was subcloned in frame with a hexa-histidine tag sequence to produce a $\mathrm{C}$-terminal His6 fusion protein. The C48S, A206C, and L221C mutations were introduced by Quick-Change site-directed mutagenesis to produce the final plasmid pGFP-QC2 (see Figure S4 for plasmid map). The sequence of the GFP-QC2 gene was verified by di-deoxy sequencing. The plasmid was used to transform the E. coli BL21(DE3) strain (New England Biolabs). For protein expression, a single colony of $E$. coli BL21(DE3) carrying the expression construct was selected and grown in LB medium supplemented with $100 \mu \mathrm{g} / \mathrm{mL}$ ampicillin at $37^{\circ} \mathrm{C}$ overnight. The next day, overnight culture was used to inoculate $1 \mathrm{~L}$ of $\mathrm{LB}$ containing $100 \mu \mathrm{g} / \mathrm{mL}$ ampicillin. At an optical density $\left(\mathrm{OD}_{600 \mathrm{~nm}}\right)$ of 0.6-0.8, expression of the GFP-QC2 cysteine mutant was induced by adding IPTG to $1 \mathrm{mM}$ and growing for $3-4 \mathrm{~h}$ at $30^{\circ} \mathrm{C}$. Following centrifugation, the cell pellet was resuspended and stored in $50 \mathrm{mM}$ Tris, $1 \mathrm{M} \mathrm{KCl}, 1 \%(\mathrm{v} / \mathrm{v})$ glycerol, $1 \mathrm{mM}$ DTT, $5 \mathrm{mM}$ imidazole ( $\mathrm{pH} 8.0)$ at $-20^{\circ} \mathrm{C}$.

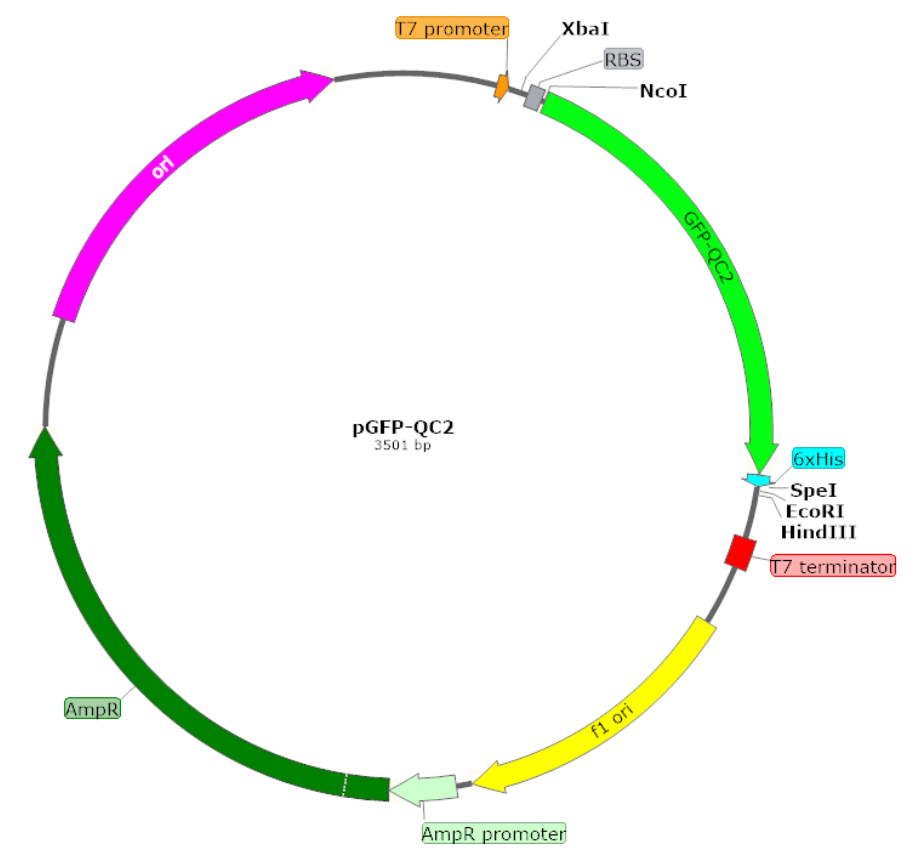

Figure S4: Physical and functional map of pGFP-QC2 plasmid. Relevant features of pGFP-QC2 are annotated on the map in different colours: T7 promoter (orange), ribosome binding site (RBS, gray box), GFP-QC2 gene (green) with C-terminal His ${ }^{6}$-tag (cyan), T7 terminator (red box), F1 origin (yellow), ampicillin resistance gene (AmpR) promoter (pale green), AmpR (dark green), and ColE1-like origin of replication (magenta). Unique restriction sites around GFP-QC2 are indicated. All genes are reported in scale over the total length of the vector. Images were obtained by the use of SnapGene software (from GSL Biotech).

Before cell lysis, if necessary, cell pellets were resuspended in $50 \mathrm{mM}$ Tris, $1 \mathrm{M} \mathrm{KCl}, 1$ $\mathrm{mM}$ DTT, $5 \mathrm{mM}$ imidazole ( $\mathrm{pH}$ 8.0). Cell lysis was performed by adding lysis buffer (50-100 
$\mu \mathrm{g} / \mathrm{mL}$ DNAse, $1 \mathrm{mM} \mathrm{MgCl} 2$ and $1 \mathrm{mM}$ DTT) followed by mechanical cell disruption using TissueLyser LT (Qiagen). After complete cell lysis, ethylenediaminetetraacetic acid (EDTA) and phenylmethylsulfonyl fluoride (PMSF) were added to final concentration of $5 \mathrm{mM}$ (pH 7.4) respectively $1 \mathrm{mM}$. Clarified extract was collected following centrifugation at 40k rpm for $1 \mathrm{~h}$ at $4^{\circ} \mathrm{C}$ (Beckman Coulter, Avanti J-20 XP Centrifuge).

His6-tagged GFP-QC2 cysteine mutant was purified from clarified extract by nickelaffinity chromatography. First, nickel resin was washed with ten volumes ethanol, MilliQ water and equilibrated with ten column volumes of Equilibration Buffer (Table S1). Clarified extract was then loaded on column followed by washing with ten column volumes of Washing Buffer (Table S1). His6-tagged GFP-QC2 cysteine mutant was then eluted from nickel column using Elution Buffer (Table S1). To evaluate purification progress, reduced samples of supernatant, flow through, wash steps and the elution steps were loaded onto SDS-PAGE gel (Figure S5).

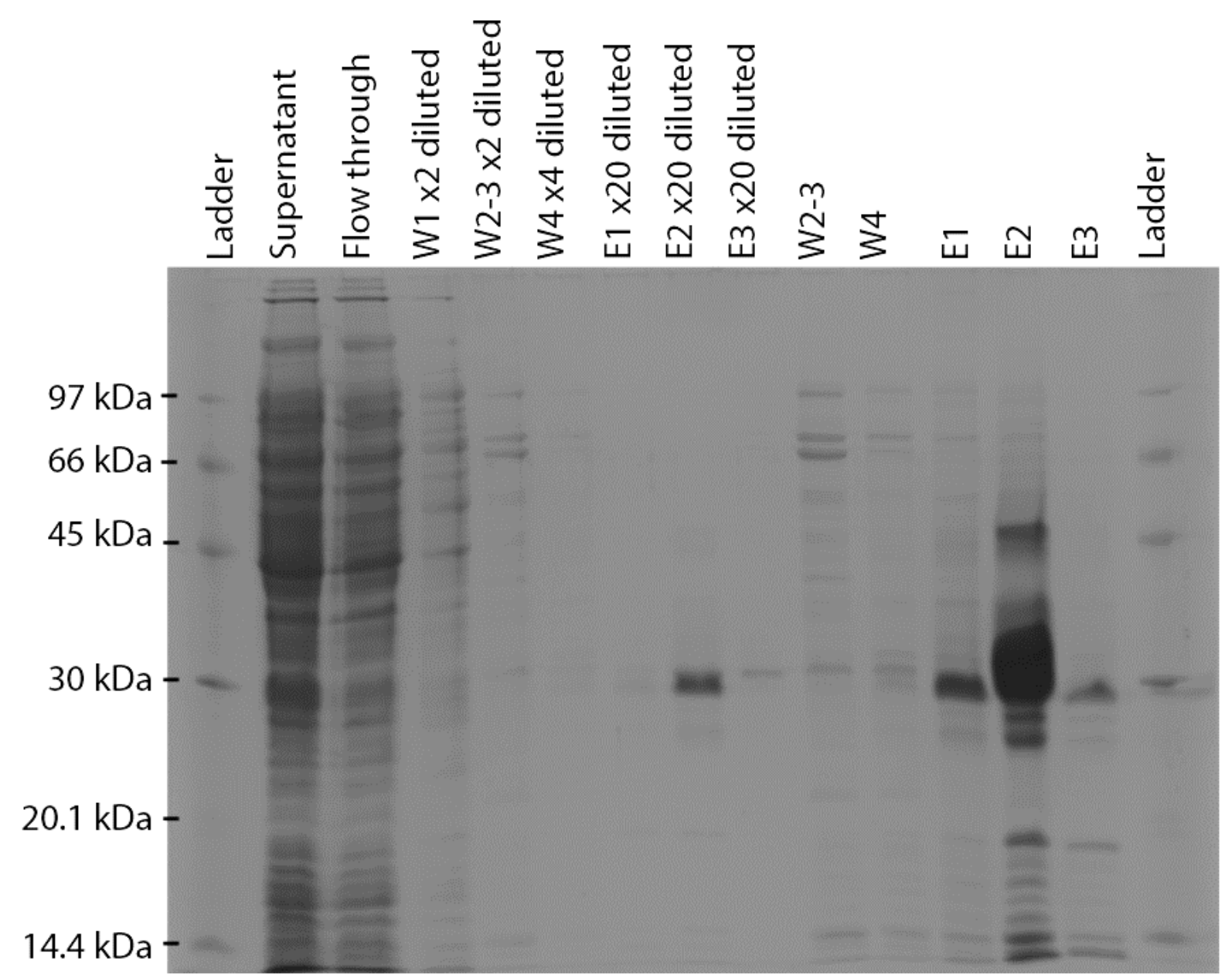

Figure S5: SDS-PAGE gel showing purification steps of GFP-QC2 using nickel-affinity column. Lanes 1: low molecular ladder (LMW-SDS Marker Kit, GE Healthcare Europe GmbH); 2: supernatant; 3: flow through; 4: wash 1 diluted by a factor of two; 5: wash 2-3 diluted by a factor of two; 6: wash 4 diluted by a factor of four; 7: elution 1 diluted by a factor of 20; 8: elution 2 diluted by a factor of 20; 9: elution 3 diluted by a factor of 20; 10: wash 23 undiluted; 11: wash 4 undiluted; 12: elution 1 undiluted; 13: elution 2 undiluted; 14: elution 3 undiluted; 15: low molecular ladder. SDS-PAGE gel was run in two intervals: $1.10 \mathrm{~min}$ at $100 \mathrm{~V}$ and 2. 60-90 min at $200 \mathrm{~V}$.

Protein eluted from nickel column was concentrated by ultrafiltration (Amicon Ultra 4, 10,000 molecular weight cut-off (MWCO), Merck KGaA). Using concentrated protein in 
dialysis system (SnakeSkin ${ }^{\mathrm{TM}}$ Dialysis Tubing, 10K MWCO, $22 \mathrm{~mm}$, Thermo Fisher Scientific), buffer was exchanged to storage buffer (50 mM Tris- $\mathrm{HCl} \mathrm{pH} 8,50 \mathrm{mM} \mathrm{KCl}, 50 \%$ (v/v) glycerol, $1 \mathrm{mM}$ DTT). Dialysis was performed in two stages at $4{ }^{\circ} \mathrm{C}$, with $\geq 12 \mathrm{~h}$ for each dialysis stage. Buffers for dialysis stage 1 and stage 2 are listed in Table S1. Following dialysis, $3 \mathrm{mM}$ EDTA (pH 7.4) and $1 \mathrm{mM}$ DTT were added and protein stock was stored at $-80{ }^{\circ} \mathrm{C}$. Protein concentration was determined by the bicinchoninic acid method (PierceTM BCA Assay Kit, Thermo Fisher Scientific) with bovine serum albumin as the standard and absorption measurements (NanoDrop ND-1000 Spectrophotometer, NanoDrop Technologies).

\section{Labelling of GFP-QC2 with photostabilizers}

GFP-QC2 cysteine was modified in a reaction with a photostabilizer-maleimide derivatives (AB-Mal, TX-Mal, NPP-Mal or COT-Mal) ${ }^{2-3}$, coupling GFP-QC2 cysteine with the maleimide group. Briefly, cysteines were first reduced by adding $5 \mu \mathrm{L}$ of $425 \mu \mathrm{M}$ GFP-QC2 (2.1 nmol) to $95 \mathrm{uL}$ of DTT-containing buffer ( $50 \mathrm{mM}$ potassium phosphate buffer [KPi buffer], $50 \mathrm{mM} \mathrm{KCl}$, $5 \%$ glycerol $[\mathrm{v} / \mathrm{v}] \mathrm{pH} 7.4,5 \mathrm{mM}$ DTT). Following $30 \mathrm{~min}$ incubation, protein solution was mixed with $1 \mathrm{~mL}$ standard buffer $(50 \mathrm{mM}$ potassium phosphate buffer [KPi buffer], $50 \mathrm{mM}$ $\mathrm{KCl}, 5 \%$ glycerol [v/v] $\mathrm{pH} 7.4$ ) and subsequently loaded on $150 \mu \mathrm{L}$ nickel resin (Ni Sepharose, 6 Fast Flow, GE Healthcare Europe $\mathrm{GmbH}$ ) equilibrated with $1 \mathrm{~mL}$ standard buffer. DTT was then washed off using ten column volumes of standard buffer. Maleimide-cysteine coupling was carried out on the resin by adding a solution of $1 \mathrm{~mL}$ standard buffer and $10 \mu \mathrm{L}$ DMSO containing $100 \mathrm{nmol}$ photostabilizer. The reaction was incubated overnight at $4{ }^{\circ} \mathrm{C}$ with gentle shaking. The next day, the resin was washed with ten column volumes of standard buffer, before eluting the protein with $1 \mathrm{~mL}$ buffer containing $500 \mathrm{mM}$ imidazole, $50 \mathrm{mM} \mathrm{KPi}, 50 \mathrm{mM} \mathrm{KCl}$, $5 \%$ glycerol (v/v). GFP-QC2 photostabilizer conjugate was further purified by size exclusion chromatography, removing excess of unbound photostabilizer, which at the same time allowed us to assess the labelling efficiency. Labelling efficiency for 4-PAM was further determined by measuring absorbance increase at $320 \mathrm{~nm}$ (Figure 3, main text).

\section{Sample preparation for single-molecule imaging}

Lab-Tek 8-well $750 \mu \mathrm{L}$ chambered cover slides (\#1.0 Borosilicate Coverglass System, Nunc/VWR, The Netherlands) were cleaned by incubating with $0.1 \mathrm{M} \mathrm{HF}$ for $10 \mathrm{~min}$ and rinsing three times with PBS buffer $(10 \mathrm{mM}$ phosphate, $2.7 \mathrm{M} \mathrm{KCl}, 137 \mathrm{mM} \mathrm{NaCl}$ at $\mathrm{pH} 7.4$, Sigma-Aldrich $)^{4}$. After cleaning, an affinity surface was generated for his 6 -tagged GFP-QC2. First, cleaned cover slides were biotinylated by incubating with a solution of $3 \mathrm{mg} / \mathrm{mL}$ BSA (Roche Diagnostics GmbH) and $1 \mathrm{mg} / \mathrm{mL}$ BSA-biotin (Sigma-Aldrich) at $7{ }^{\circ} \mathrm{C}$ for 3-4 h. After rinsing with PBS, cover slides were incubated with $0.2 \mathrm{mg} / \mathrm{mL}$ streptavidin dissolved in PBS for $10 \mathrm{~min}$ at room temperature, binding streptavidin to biotinylated surface ${ }^{5}$. Non-bound streptavidin was washed off with PBS. Finally, each chamber was incubated with $1 \mu \mathrm{L}$ Penta·His 6 Biotin Conjugate (Qiagen) in $200 \mu \mathrm{L}$ deionized water for $10 \mathrm{~min}$ and subsequently rinsed with PBS buffer. Derivatization steps resulted in free Penta His $_{6}$ groups on the surface (Figure S6), forming an affinity surface for his6-tagged protein.

Immobilisation of his 6 -tagged GFP-QC2 and photostabilizer-protein conjugates allows the characterization of photophysical properties. To homogeneously cover the glass surface, 20 
$\mu \mathrm{L}$ of $5 \mathrm{nM}$ GFP sample in $200 \mu \mathrm{L}$ MilliQ water were added to a chamber which was subsequently rinsed with a high concentrated salt solution $(1 \mathrm{M} \mathrm{KPi})$ and $\mathrm{PBS}^{4}$. If applicable, buffer was deoxygenated in chambers ${ }^{4}$ by using an oxygen scavenging system (PBS buffer at pH 7.4 including $1 \%(\mathrm{w} / \mathrm{v})$ glucose and $10 \%$ (w/v) glycerol, $50 \mu \mathrm{g} / \mathrm{mL}$ glucose oxidase, 100 $200 \mu \mathrm{g} / \mathrm{mL}$ catalase, $0.1 \mathrm{mM}$ tris(2-carboxyethyl)phosphine hydrochloride [TCEP]) for which the chambers were sealed with adhesive tape (Adhesive silicon sheet JTR-SA2-2.5, Grace BioLabs).

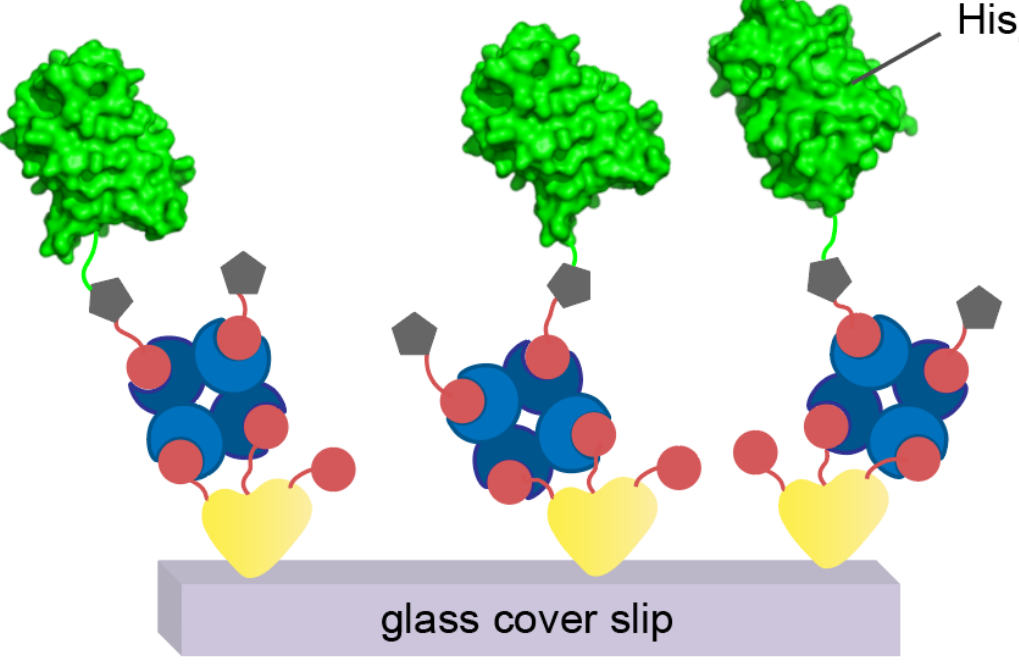
$\mathrm{His}_{6}$-tagged GFP-QC2 mutant

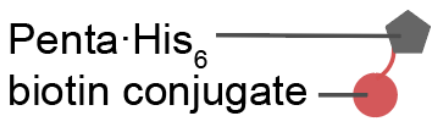

Figure S6: Immobilisation of GFP-QC2 on a affinity-surface, prepared on Lab-Tek coverglass system.

\section{Spectroscopy \& Quantum yield determination}

Absorbance spectra were recorded using absorption spectrometer V-630 (wavelength accuracy $\pm 0.2 \mathrm{~nm}$, photometric accuracy \pm 0.002 Abs. [0 to 0.5 Abs.] and \pm 0.002 Abs. [0.5 to 1 Abs.], JASCO) and quartz glass cuvettes (precision cuvettes made of quartz glass Model FP-1004, d $=1 \mathrm{~cm}$, JASCO parts center). Fluorescence spectra were recorded with the fluorescence spectrometer FP-8300 (wavelength accuracy $\pm 1.5 \mathrm{~nm}, \mathrm{JASCO}$ ) and quartz glass cuvettes (precision cuvettes made of quartz glass Model FP-1004, $\mathrm{d}=1 \mathrm{~cm}$, JASCO parts center).

Fluorescence quantum yields were determined for eGFP and GFP-QC2 with $1 \mathrm{mM}$ and without TCEP in PBS in comparison to the quantum yield standard fluorescein in $0.1 \mathrm{M} \mathrm{NaOH}^{6}$. The absorbance spectra and emission spectra obtained via $488 \mathrm{~nm}$ excitation were recorded for five different fluorophore/protein concentrations. Absorbance spectra were base-line corrected to remove buffer background. Emission spectra were corrected for wavelength-dependent detection efficiency and excitation scattering light. The integrated fluorescence $I_{F}=$ $\int_{0}^{\infty} F_{D}(\lambda) d \lambda$ was obtained by recording the emission spectra $F_{D}(\lambda)$ introducing corrections for reabsorbance of the fluorescence. We estimated this via $I_{F}\left(A_{488}\right)=m A_{488} \cdot 10^{-\frac{A_{488}}{2}}$, where the factor $10^{-\frac{A_{488}}{2}}$ accounts for the absorption of excitation light during emission measurements.

The absolute fluorescence quantum yield of the GFP proteins (eGFP, GFP-QC2) were calculated from the slopes of the fits of GFP $m_{G F P}$ and fluorescein $m_{f l c n}$ as 


$$
\boldsymbol{\Phi}_{G F P}=\frac{m_{G F P}}{m_{f l c n}} \boldsymbol{\Phi}_{f l c n}
$$

We obtained $\boldsymbol{\Phi}_{\text {flcn }}=92.5 \%$ from the literature ${ }^{6}$. The reported values and standard deviations resulted from three independent experiments.

\section{Single-molecule TIRF imaging}

Widefield fluorescence and TIRF imaging was performed on an inverted microscope (Olympus IX-71 with UPlanSApo 100x, NA 1.49, Olympus, Germany) in an objective type total-internalreflection fluorescence (TIRF) configuration. The images were collected with a backilluminated emCCD camera (512x512 pixel, C9100-13, Hammamatsu, Japan in combination with ET535/70, AHF Analysentechnik, Germany). Excitation is conducted from a diode laser (Sapphire and Cube, Coherent, Germany) at $488 \mathrm{~nm}$ with $\approx 0.4-3.2 \mathrm{~kW} / \mathrm{cm}^{2}$ at the sample location. The imaging area covers a size of $\approx 25 \times 35 \mu \mathrm{m}$ containing $>40$ proteins and the full chip amounts to $50 \times 50 \mu \mathrm{m}$. The recorded movies range over $100-180 \mathrm{~s}$ with an integration time of either $50 \mathrm{~ms}$ or $100 \mathrm{~ms}$. Fluorescence time traces were extracted from pixels which showed at least 2-3 standard deviations above background noise (standard deviation of all pixels over all frames of the movie) and summing the intensity in a $3 \times 3$ pixel area. Neighbouring peaks closer than 5 pixels were not taken into account. The number of fluorescent spots in each frame image was determined using an absolute threshold criterion. The number of proteins per image are plotted over time [s] and fitted to a mono-exponential decay $y(t)=C+A \cdot e^{\wedge}(-b t)$ (with $b=$ $1 / \tau_{\text {bleach }}$ and $\tau_{\text {bleach }}$ being the characteristic bleaching time constant). Using these fluorescent time traces, four photophysical properties were measured: 1.) Bleaching times and corresponding standard deviations were derived from multiple repeats of the same measurement on different days, where each condition was tested $\geq 2$ movies. 2.) Signal-to-noise (SNR) ratio was determined by dividing the standard deviation of the signal before photobleaching with the average fluorescence intensity during that period. 3.) Count rate, respectively brightness, was obtained by multiplying the signal (counts / $100 \mathrm{~ms} / \mathrm{pixel}$ ) by 10 to receive counts / s / pixel, by 9 to gain counts / s and by 111.14 to obtain photons / s (conversion from counts to photons is a device-specific value for CCD camera). 4.) Total number of detected photons before bleaching were calculated by multiplying the count rate by $\tau_{\text {bleach. }}$. 
bioRxiv preprint doi: https://doi.org/10.1101/2020.03.07.980722; this version posted March 7, 2020. The copyright holder for this preprint (which was not certified by peer review) is the author/funder. All rights reserved. No reuse allowed without permission.

SI for Henrikus et al. - Characterization of fluorescent proteins with intramolecular photostabilization

Table S1: Buffers and solutions and their final concentrations.

\begin{tabular}{|c|c|}
\hline Buffer & Composition \\
\hline Equilibration Buffer & $\begin{array}{l}50 \mathrm{mM} \text { Tris- } \mathrm{HCl}, \mathrm{pH} 8 \\
1 \mathrm{M} \mathrm{KCl} \\
1 \%(\mathrm{v} / \mathrm{v}) \text { glycerol } \\
1 \mathrm{mM} \text { DTT } \\
5 \mathrm{mM} \text { imidazole }\end{array}$ \\
\hline Wash Buffer & $\begin{array}{l}50 \mathrm{mM} \text { Tris- } \mathrm{HCl}, \mathrm{pH} 8 \\
100 \mathrm{mM} \mathrm{KCl} \\
2 \%(\mathrm{v} / \mathrm{v}) \text { glycerol } \\
1 \mathrm{mM} \text { DTT } \\
40 \mathrm{mM} \text { imidazole }\end{array}$ \\
\hline Elution Buffer & $\begin{array}{l}50 \mathrm{mM} \text { Tris- } \mathrm{HCl}, \mathrm{pH} 8 \\
100 \mathrm{mM} \mathrm{KCl} \\
2 \%(\mathrm{v} / \mathrm{v}) \text { glycerol } \\
10 \mathrm{mM} \text { DTT } \\
300 \mathrm{mM} \text { imidazole }\end{array}$ \\
\hline Dialysis 1 & $\begin{array}{l}50 \mathrm{mM} \text { Tris- } \mathrm{HCl}, \mathrm{pH} 8 \\
50 \mathrm{mM} \mathrm{KCl} \\
5 \%(\mathrm{v} / \mathrm{v}) \text { glycerol } \\
1 \mathrm{mM} \mathrm{DTT}\end{array}$ \\
\hline Dialysis 2 & $\begin{array}{l}50 \mathrm{mM} \text { Tris- } \mathrm{HCl}, \mathrm{pH} 8 \\
50 \mathrm{mM} \mathrm{KCl} \\
50 \%(\mathrm{v} / \mathrm{v}) \text { gylcerol } \\
1 \mathrm{mM} \mathrm{DTT}\end{array}$ \\
\hline Stacking Buffer & $\begin{array}{l}0.5 \mathrm{M} \text { Tris- } \mathrm{HCl}, \mathrm{pH} 6.6 \\
10 \%(\mathrm{w} / \mathrm{v}) \text { sodium dodecyl sulfate (SDS) }\end{array}$ \\
\hline Separation Buffer & $\begin{array}{l}4.5 \mathrm{M} \text { Tris-HCl, } \mathrm{pH} 8.8 \\
10 \%(\mathrm{w} / \mathrm{v}) \mathrm{SDS}\end{array}$ \\
\hline SDS-Loading Buffer & $\begin{array}{l}250 \mathrm{mM} \text { Tris-HCl, pH } 6.6 \\
10 \%(\mathrm{w} / \mathrm{v}) \mathrm{SDS} \\
0.2 \%(\mathrm{w} / \mathrm{v}) \text { bromophenol blue } \\
12.5 \%(\mathrm{w} / \mathrm{v}) \beta \text {-mercaptoethanol } \\
50 \%(\mathrm{v} / \mathrm{v}) \text { glycerol }\end{array}$ \\
\hline SDS-Running Buffer & $\begin{array}{l}250 \mathrm{mM} \text { Tris } \\
1.92 \mathrm{M} \text { glycine } \\
1 \%(\mathrm{w} / \mathrm{v}) \mathrm{SDS}\end{array}$ \\
\hline Coomassie Brilliant Blue & $\begin{array}{l}0.125 \%(\mathrm{w} / \mathrm{v}) \text { Coomassie } \mathrm{R} \\
40 \%(\mathrm{v} / \mathrm{v}) \text { ethanol } \\
5 \%(\mathrm{v} / \mathrm{v}) \text { acetic acid }\end{array}$ \\
\hline
\end{tabular}




\section{Synthesis and characterization of photostabilizer-maleimide derivatives}

\section{$\underline{A B-M a l}$}

4-phenylazomaleinanil (4-PAM, see Figure S1) was purchased from Sigma Aldrich (CAS Number 103-33-3) with $98 \%$ purity.

\section{$\underline{N P P-M a l}$}

NPP-Mal was obtained by coupling 3-(4-nitrophenyl)propanoic acid (NPP) with 1-(2aminoethyl)-1H-pyrrole-2,5-dione (maleimide amine, Mal- $\mathrm{NH}_{2}$ ) following a modified procedure $^{7}$ (see Figure S7). Briefly, NPP (1.0 equiv, $20.1 \mathrm{mg}, 0.1 \mathrm{mmol}$ ) and Mal-NH2 (3.6 equiv, $93.3 \mathrm{mg}, 0.37 \mathrm{mmol}$ ) were dissolved in $1 \mathrm{~mL}$ DMF and HATU (5.2 equiv, $0.21 \mathrm{~g}, 0.54$ mmol) in $0.5 \mathrm{~mL}$ DMF was added.

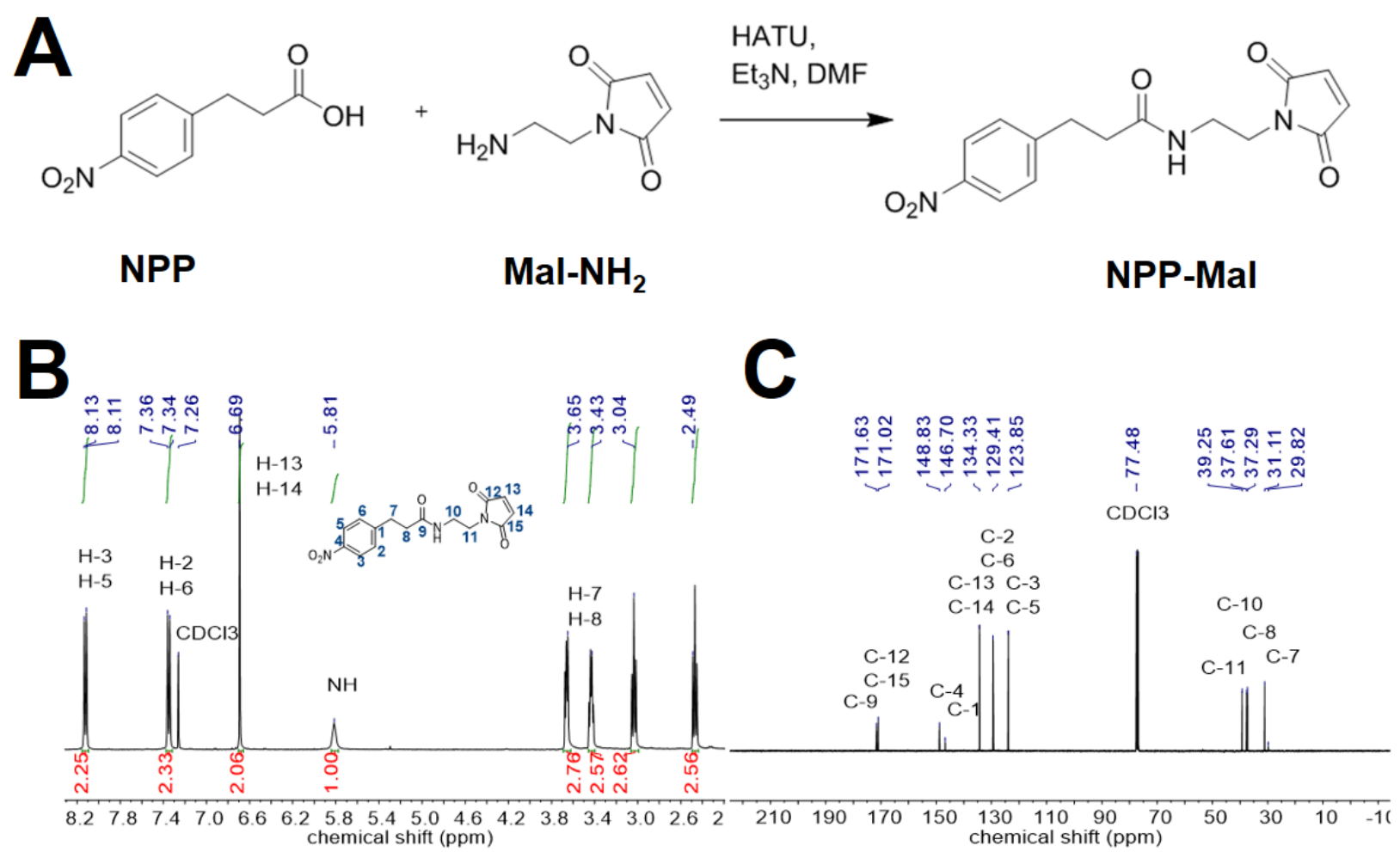

Figure S7: (A) Coupling scheme for synthesis of NPP-Mal. (B) ${ }^{1} \mathrm{H}$ spectrum and (C) ${ }^{13} \mathrm{C}$ spectrum of NPP-Mal.

Then, $\mathrm{Et}_{3} \mathrm{~N}(50 \mu \mathrm{L})$ was added dropwise to the solution and the reaction mixture was stirred at room temperature for $19.5 \mathrm{~h}$. The reaction mixture was concentrated and the crude product was purified by column chromatography ( $\mathrm{SiO} 2, \mathrm{DCM} / \mathrm{MeOH} 99: 1)$ yielding a yellowish solid (30.3 $\mathrm{mg}, 0.09 \mathrm{mmol}, 93 \%)$. The product was characterized by NMR spectroscopy and mass spectrometry (see Figure S7).

${ }^{1} \mathrm{H}$ NMR (400 MHz, CDCl3) $\delta=8.13$ (s, 1H, H-3), 8.11 (s, 1H, H-5), 7.36 (s, 1H, H-2), 7.34 (s, 1H, H-6), 6.69 (s, 2H, H-13, H-14), 5.81 (br s, 1H, NH), 3.65 (tr, J = 5.3 Hz, 2H, H-7), 3.43 (quart, $J=5.2 \mathrm{~Hz}, 2 \mathrm{H}, \mathrm{H}-8), 3.04(\operatorname{tr}, J=7.7 \mathrm{~Hz}, 2 \mathrm{H}, \mathrm{H}-11$ ), 2.49 (tr, $J=7.7 \mathrm{~Hz}, 2 \mathrm{H}, \mathrm{H}-$ 10) $\mathrm{ppm}$. 
${ }^{13} \mathrm{C}$ NMR $(200 \mathrm{MHz}, \mathrm{CDCl} 3) \delta=171.63(\mathrm{C}-9), 171.02(\mathrm{C}-12, \mathrm{C}-15), 148.83(\mathrm{C}-4)$, 146.70 (C- 1), 134.33 (C-13, C-14), 129.41 (C-2, C-6), 123.85 (C-3, C-5), 39.25 (C-11), 37.61 (C-10), 37.29 (C-8), 31.11 (C-7) ppm.

Mass spectrometry (ESI, full scan) $\mathrm{m} / \mathrm{z}$ calculated 317.29682 , found $318.10846[\mathrm{M}+\mathrm{H}]^{+}$, $340.09034[\mathrm{M}+\mathrm{Na}]^{+}, 356.06425[\mathrm{M}+\mathrm{K}]^{+}$.

\section{$\underline{T X-M a l}$}

TX-Mal was obtained in a two-step reaction. Frist, Trolox-NHS was synthesized following a modified procedures ${ }^{2,8}$. Trolox (TX) $(1.0$ equiv, $0.282 \mathrm{~g}, 1.13 \mathrm{mmol})$ and $\mathrm{N}$ hydroxysuccinimide (NHS) (1.2 eqiv, $0.251 \mathrm{~g}, 1.33 \mathrm{mmol}$ ) were dissolved in $4.5 \mathrm{~mL} 1$,4dioxane. The reaction mixture was cooled to $0^{\circ} \mathrm{C}$ and $N, N^{\prime}$-dicyclohexyl carbodiimide (DCC) ( 0.7 equiv, $0.155 \mathrm{~g}, 0.75 \mathrm{mmol}$ ) was added. The resulting mixture was allowed to warm up to room temperature and stirred for $19 \mathrm{~h}$. Following reaction, the mixture was cooled to $10{ }^{\circ} \mathrm{C}$, filtered and concentrated. To remove residue 1,4-dioxane, anhydrous ethanol was added and evaporated. The crude prodcut was purified by column chromatography ( $\mathrm{SiO} 2, \mathrm{DCM} / \mathrm{MeOH}$ 99:1) to produce a white solid of TX-NHS $(65.2 \mathrm{mg}, 0.19 \mathrm{mmol}, 17 \%)$. The product was confirmed by NMR spectroscopy: ${ }^{1} \mathrm{H}$ NMR $(400 \mathrm{MHz}, \mathrm{CDCl} 3) \delta=2.73$ (s, 4H, H-16, H-17), 2.69-2.66 (m, 1H, H-3a), 2.58-2.53 (m, 1H, H-3b), 2.15 (s, 3H, H-11), 2.13 (s, 3H, H-12), 2.07 (s, 3H, H-10), 2.04-1.96 (m, 1H, H-2), 1.82 (s, 3H, H-13) ppm.

To generate TX-Mal, purified Trolox-NHS was coupled with 1-(2-aminoethyl)- $1 \mathrm{H}$ pyrrole-2,5-dione (Mal-NH ${ }_{2}$ ) following a published procedure ${ }^{2}$ (see Figure S8A). TX-Mal (1.0 equiv, $0.065 \mathrm{~g}, 0.19 \mathrm{mmol}$ ) was dissolved in $2.5 \mathrm{~mL}$ DMF and a solution of $\mathrm{Mal}_{-} \mathrm{NH}_{2}(1.5$ equiv, $0.072 \mathrm{~g}, 0.51 \mathrm{mmol})$ and $\mathrm{Et} 3 \mathrm{~N}(50 \mu \mathrm{L})$ in $1.5 \mathrm{~mL}$ DMF was added. This mixture was stirred for $18 \mathrm{~h}$ at room temperature. At that point, $1 \mathrm{~mL}$ of water was added and the solution was acidified with $\mathrm{H}_{2} \mathrm{SO}_{4}$ to $\mathrm{pH}$ 1. The reaction mixture was extracted with EtOAc $(3 \times 5 \mathrm{~mL})$, the combined organic phases were dried over Na2SO4 and concentrated. The crude product was purified by gradient column chromatography ( $\mathrm{SiO} 2, \mathrm{DCM} / \mathrm{MeOH}$ 99:1 - 95:5) to amount to a yellowish solid $(2.8 .9 \mathrm{mg}, 0.08 \mathrm{mmol}, 41 \%)$. The product TX-Mal was confirmed by NMR spectroscopy and mass spectrometry.

${ }^{1} \mathrm{H}$ NMR $(400 \mathrm{MHz}, \mathrm{CDCl} 3) \delta=8.01(\mathrm{~s}, 1 \mathrm{H}, \mathrm{NH}), 6.62(\mathrm{~s}, 1 \mathrm{H}, \mathrm{OH}), 6.57(\mathrm{~s}, 2 \mathrm{H}, \mathrm{H}-18$, H-19), 3.72 - 3.37 (m, 4H, H-2, H-3), 2.95 (s, 2H, H-16), 2.88 (s, 2H, H-15), 2.16 (s, 6H, H11, H-12), 2.07 (s, 3H, H-10), 1.45 (s, 3H, H-13) ppm.

${ }^{13} \mathrm{C}$ NMR (400 MHz, CDCl3) $\delta=175.09$ (C-14), 170.66 (C-17, C-20), 145.63 (C-6), 144.26 (C- 9), 133.95 (C-18, C-19), 122.18 (C-7), 121.45 (C-5), 119.02 (C-4), 118.09 (C-8), 78.36 (C-1), 37.97 (C-16), 37.40 (C-15), 29.51 (C-3), 24.53 (C-2), 20.55 (C-13), 12.38 (C-10), $12.10(\mathrm{C}-11), 11.46(\mathrm{C}-12) \mathrm{ppm}$.

Mass spectrometry (ESI, full scan) $\mathrm{m} / \mathrm{z}$ calculated 372.41504 , found 373.17508 $[\mathrm{M}+\mathrm{H}]^{+}, 395.15694[\mathrm{M}+\mathrm{Na}]^{+}, 411.15176[\mathrm{M}+\mathrm{K}]^{+}, 767.32478[\mathrm{M} 2+\mathrm{Na}]^{+}$. 
A<smiles>CCN(CC)CC[C@H](C)CC1=CC(=O)N(CCN)C1=O</smiles>
TX-NHS

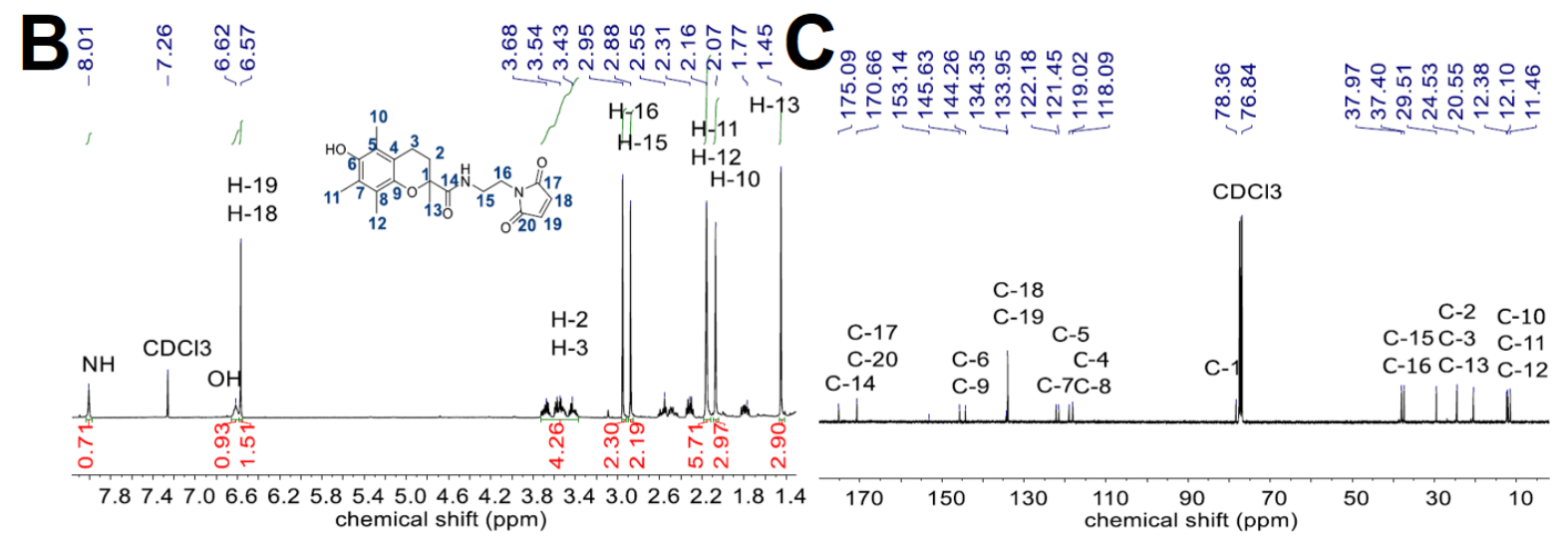

Figure S8: (A) Coupling scheme for synthesis of TX-Mal. (B) ${ }^{1} \mathrm{H}$ spectrum and (C) ${ }^{13} \mathrm{C}$ spectrum TX-Mal.

\section{$\underline{\text { COT-Mal }}$}

COT-Mal was synthesized by forming an amide bond between $\mathrm{COT}-\mathrm{COOH}$ and $\mathrm{Mal}-\mathrm{NH}_{2}$ (see Figure S9A), following a modified published procedure ${ }^{2}$. Educt COT-COOH was previously synthesized ${ }^{9}$. Mal-NH 2 (1.0 equiv, $30.2 \mathrm{mg}, 0.12 \mathrm{mmol}$ ) and COT-COOH (1.1 equiv, $22.1 \mathrm{mg}$, $0.13 \mathrm{mmol}$ ) were dissolved in $1 \mathrm{~mL}$ DMF and HATU (5.8 equiv, $0.26 \mathrm{~g}, 0.69 \mathrm{mmol}$ ) in $1.0 \mathrm{~mL}$ DMF was added. Then, Et3N $(50 \mu \mathrm{L})$ was added dropwise to the solution and the reaction mixture was stirred at room temperature for $19.5 \mathrm{~h}$. The reaction mixture was concentrated and the crude product was purified by column chromatography ( $\mathrm{SiO} 2, \mathrm{DCM} / \mathrm{MeOH} 98: 2$ ) to yield a yellowish solid (13.0 mg, $0.03 \mathrm{mmol}, 25 \%)$.

${ }^{1} \mathrm{H}$ NMR (400 MHz, CDCl3) $\delta=6.72$ (s, 2 H, H-15, H-16), 5.92 (br s, 1H, NH), $5.88-$ 5.67 (m, 6H, H-3, H-4, H-5, H-6, H-7, H-8), 5.60 (s, 1H, H-2), 3.69 (tr, J = 5.5 Hz, 2H, H-13), 3.46 (quart, $J=5.5 \mathrm{~Hz}, 2 \mathrm{H}, \mathrm{H}-12$ ), $2.37-2.28$ (m, $2 \mathrm{H}, \mathrm{H}-10), 2.28-2.21$ (m, 2H, H-9) ppm.

${ }^{13} \mathrm{C}$ NMR (400 MHz, CDCl3) $\delta=172.84$ (C-11), 171.01 (C-14, C-17), 142.97 (C-1), 134.37 (C- 15, C-16), 133.81 (C-5), 132.30 (C-4, C-6), 132.22 (C-3), 131.80 (C-7), 131.24 (C2), 127.77 (C-8), 38.91 (C-13), 37.76 (C-12), 35.80 (C-10), 33.51 (C-9) ppm.

Mass spectometry (ESI, full scan) $\mathrm{m} / \mathrm{z}$ calculated 298.3365, found $299.13827[\mathrm{M}+\mathrm{H}]^{+}$, $321.12000[\mathrm{M}+\mathrm{Na}]^{+}$. 
A<smiles>O=C(O)CCC1=CC=CC=CC=C1</smiles>

B

COT-COOH

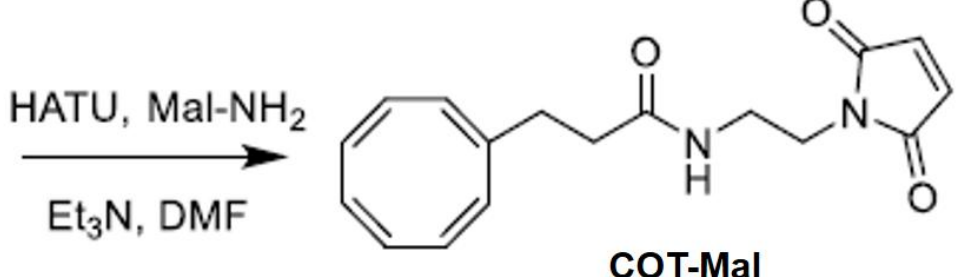

COT-Mal
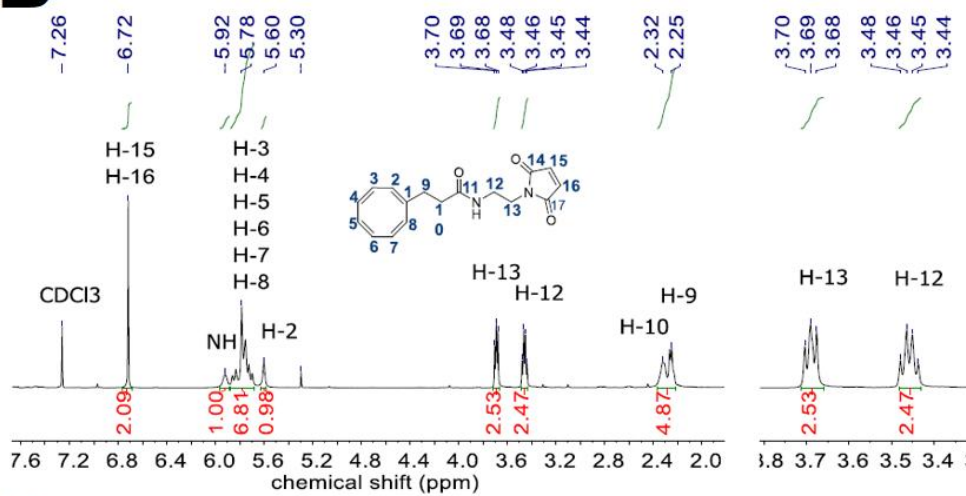

$\mathrm{H}-13 \quad \mathrm{H}-12$

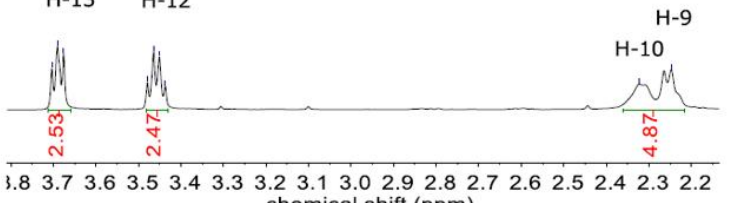

$3.83 .73 .63 .53 .43 .3 \begin{aligned} & 3 \\ & \text { chemical shift }(\mathrm{ppm})\end{aligned}$
chem

C

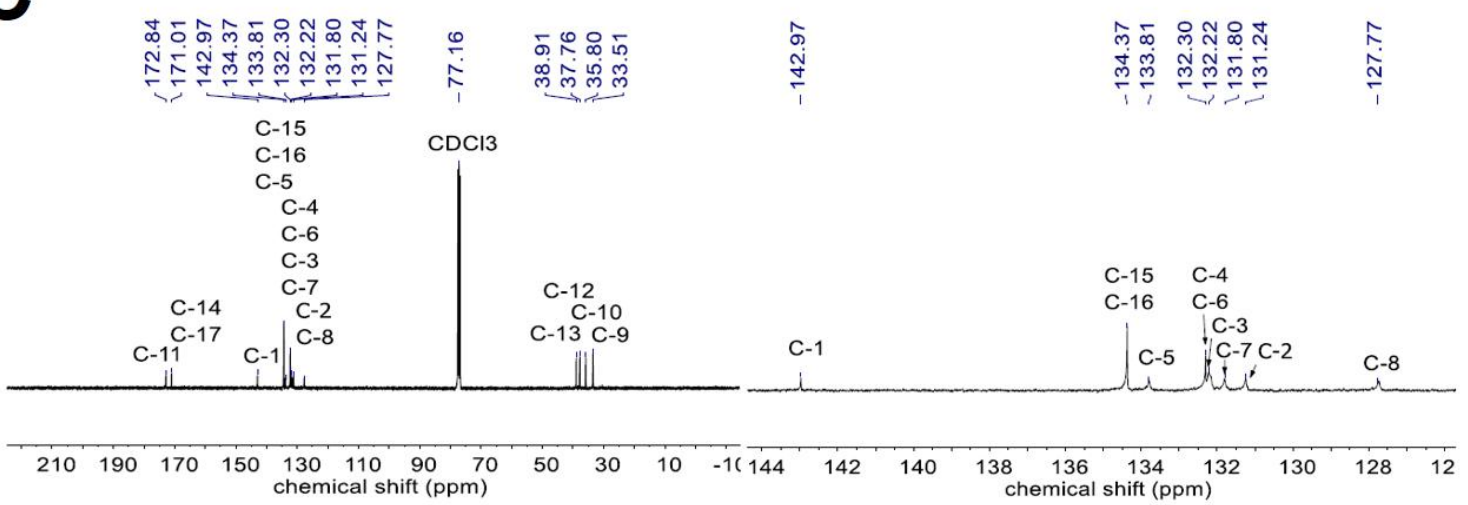

Figure S9: (A) Coupling scheme for synthesis of COT-Mal. (B) ${ }^{1} \mathrm{H}$ spectrum and (C) ${ }^{13} \mathrm{C}$ spectrum of COT-Mal. 


\section{Supporting Information References}

1. Crameri, A.; Whitehorn, E. A.; Tate, E.; Stemmer, W. P., Improved Green Fluorescent Protein by Molecular Evolution Using DNA Shuffling. Nature biotechnology 1996, 14, $315-$ 319.

2. van der Velde, J. H.; Oelerich, J.; Huang, J.; Smit, J. H.; Jazi, A. A.; Galiani, S.; Kolmakov, K.; Gouridis, G.; Eggeling, C.; Herrmann, A., A Simple and Versatile Design Concept for Fluorophore Derivatives with Intramolecular Photostabilization. Nature communications 2016, 7, 10144.

3. Gouridis, G.; Schuurman-Wolters, G. K.; Ploetz, E.; Husada, F.; Vietrov, R.; De Boer, M.; Cordes, T.; Poolman, B., Conformational Dynamics in Substrate-Binding Domains Influences Transport in the Abc Importer Glnpq. Nature Structural \& Molecular Biology 2015, 22,57 .

4. Vogelsang, J.; Kasper, R.; Steinhauer, C.; Person, B.; Heilemann, M.; Sauer, M.; Tinnefeld, P., A Reducing and Oxidizing System Minimizes Photobleaching and Blinking of Fluorescent Dyes. Angewandte Chemie International Edition 2008, 47, 5465-5469.

5. $\quad$ van der Velde, J. H.; Ploetz, E.; Hiermaier, M.; Oelerich, J.; de Vries, J. W.; Roelfes, G.; Cordes, T., Mechanism of Intramolecular Photostabilization in Self $\square$ Healing Cyanine Fluorophores. ChemPhysChem 2013, 14, 4084-4093.

6. Magde, D.; Wong, R.; Seybold, P. G., Fluorescence Quantum Yields and Their Relation to Lifetimes of Rhodamine $6 \mathrm{G}$ and Fluorescein in Nine Solvents: Improved Absolute Standards for Quantum Yields. Photochemistry and Photobiology 2002,75, 327-334.

7. $\quad$ van der Velde, J. H.; Oelerich, J.; Huang, J.; Smit, J. H.; Hiermaier, M.; Ploetz, E.; Herrmann, A.; Roelfes, G.; Cordes, T., The Power of Two: Covalent Coupling of Photostabilizers for Fluorescence Applications. The journal of physical chemistry letters 2014, 5, 3792-3798.

8. Koufaki, M.; Detsi, A.; Theodorou, E.; Kiziridi, C.; Calogeropoulou, T.; Vassilopoulos, A.; Kourounakis, A. P.; Rekka, E.; Kourounakis, P. N.; Gaitanaki, C., Synthesis of Chroman Analogues of Lipoic Acid and Evaluation of Their Activity against Reperfusion Arrhythmias. Bioorganic \& medicinal chemistry 2004, 12, 4835-4841.

9. Smit, J. H.; van der Velde, J. H.; Huang, J.; Trauschke, V.; Henrikus, S. S.; Chen, S.; Eleftheriadis, N.; Warszawik, E. M.; Herrmann, A.; Cordes, T., On the Impact of Competing Intra-and Intermolecular Triplet-State Quenching on Photobleaching and Photoswitching Kinetics of Organic Fluorophores. Physical Chemistry Chemical Physics 2019, 21, 3721-3733. 